\title{
MERCURY CONTROL WITH THE ADVANCED HYBRID PARTICULATE COLLECTOR
}

\section{Technical Progress Report}

for the period October 1 through December 31, 2001

Prepared for:

AAD Document Control

U.S. Department of Energy

National Energy Technology Laboratory

PO Box 10940, MS 921-107

Pittsburgh, PA 15236-0940

DOE Cooperative Agreement DE-FC26-01NT41184; UND Fund 4498

Performance Monitor: William Aljoe

Prepared by:

Ye Zhuang

Stanley J. Miller

Grant E. Dunham Michelle R. Olderbak

Energy \& Environmental Research Center

University of North Dakota

PO Box 9018

Grand Forks, ND 58202-9018

February 2002 


\section{EERC DISCLAIMER}

LEGAL NOTICE This research report was prepared by the Energy \& Environmental Research Center (EERC), an agency of the University of North Dakota, as an account of work sponsored by National Energy Technology Laboratory. Because of the research nature of the work performed, neither the EERC nor any of its employees makes any warranty, express or implied, or assumes any legal liability or responsibility for the accuracy, completeness, or usefulness of any information, apparatus, product, or process disclosed, or represents that its use would not infringe privately owned rights. Reference herein to any specific commercial product, process, or service by trade name, trademark, manufacturer, or otherwise does not necessarily constitute or imply its endorsement or recommendation by the EERC.

\section{DISCLAIMER}

This report was prepared as an account of work sponsored by an agency of the United States Government. Neither the United States Government, nor any agency thereof, nor any of their employees makes any warranty, express or implied, or assumes any legal liability or responsibility for the accuracy, completeness, or usefulness of any information, apparatus, product, or process disclosed or represents that its use would not infringe privately owned rights. Reference herein to any specific commercial product, process, or service by trade name, trademark, manufacturer, or otherwise does not necessarily constitute or imply its endorsement, recommendation, or favoring by the United States Government or any agency thereof. The views and opinions of authors expressed herein do not necessarily state or reflect those of the United States Government or any agency thereof.

This report is available to the public from the National Technical Information Service, U.S. Department of Commerce, 5285 Port Royal Road, Springfield, VA 22161; phone orders accepted at (703) 487-4650.

\section{ACKNOWLEDGMENT}

This report was prepared with the support of the U.S. Department of Energy (DOE) National Energy Technology Laboratory Cooperative Agreement No. DE-FC26-01NT41184. However, any opinions, findings, conclusions, or recommendations expressed herein are those of the author(s) and do not necessarily reflect the views of DOE. 


\title{
MERCURY CONTROL WITH THE ADVANCED HYBRID PARTICULATE COLLECTOR
}

\begin{abstract}
This project was awarded under U.S. Department of Energy (DOE) Program Solicitation DE-PS26-00NT40769 and specifically addresses Technical Topical Area 4 - Testing Novel and Less Mature Control Technologies on Actual Flue Gas at the Pilot Scale. The project team includes the Energy \& Environmental Research Center (EERC) as the main contractor; W.L. Gore \& Associates, Inc., as a technical and financial partner; and the Big Stone Power Plant operated by Otter Tail Power Company, which will host the field testing portion of the research.

Since 1995, DOE has supported development of a new concept in particulate control, called the advanced hybrid particulate collector (AHPC). The AHPC combines the best features of electrostatic precipitators (ESPs) and baghouses in a unique configuration, providing major synergism between the two collection methods, both in the particulate collection step and in the transfer of dust to the hopper. The AHPC provides ultrahigh collection efficiency, overcoming the problem of excessive fine-particle emission with conventional ESPs, and it solves the problem of reentrainment and re-collection of dust in conventional baghouses. The AHPC appears to have unique advantages for mercury control over baghouses or ESPs as an excellent gas-solid contactor.

The objective of the three-task project is to demonstrate $90 \%$ total mercury control in the AHPC at a lower cost than current mercury control estimates. The approach includes bench-scale batch testing that ties the new work to previous results and links results with larger-scale pilot testing with real flue gas on a coal-fired combustion system, pilot-scale testing on a coal-fired combustion system with both a pulse-jet baghouse and an AHPC to prove or disprove the research hypotheses, and field demonstration pilot-scale testing at a utility power plant to prove scaleup and demonstrate longer-term mercury control.

This project, if successful, will demonstrate at the pilot-scale level a technology that would provide a cost-effective technique to accomplish control of mercury emissions and, at the same time, greatly enhance fine particulate collection efficiency. The technology can be used to retrofit systems currently employing inefficient ESP technology as well as for new construction, thereby providing a solution to a large segment of the U.S. utility industry as well as other industries requiring mercury control.
\end{abstract}




\section{TABLE OF CONTENTS}

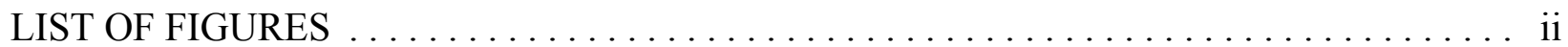

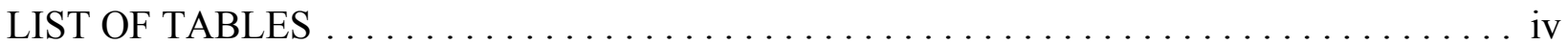

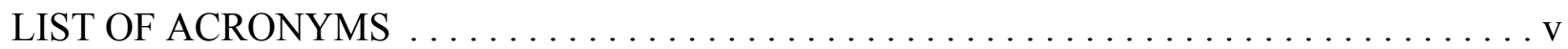

EXECUTIVE SUMMARY $\ldots \ldots \ldots \ldots \ldots \ldots \ldots \ldots \ldots \ldots \ldots \ldots$ vi

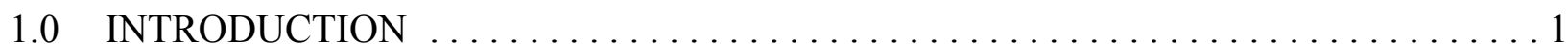

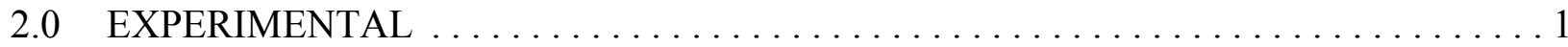

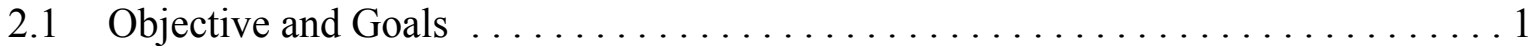

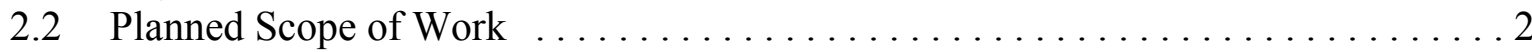

2.3 Initial Field Test with a 2.5-MW AHPC at the Big Stone Power Plant $\ldots \ldots \ldots \ldots 2$

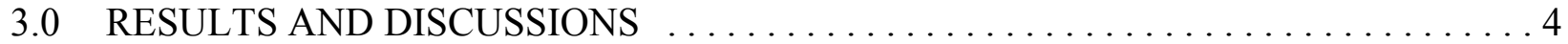

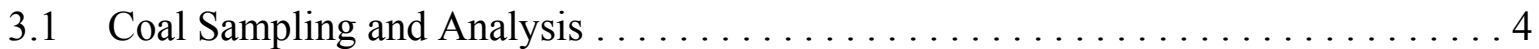

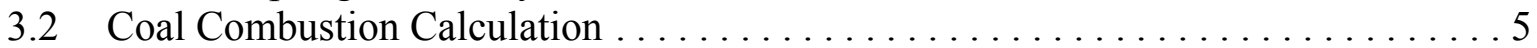

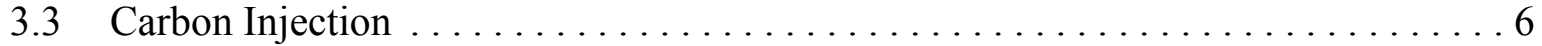

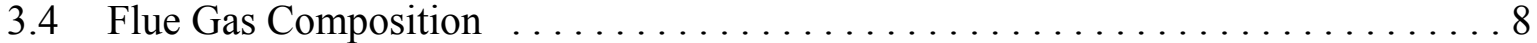

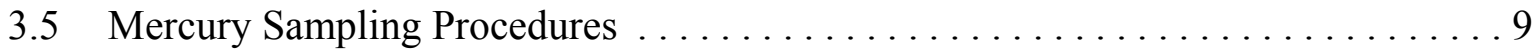

3.5.1 Ontario Hydro Mercury Speciation Method ................. 9

3.5.2 Mercury CEM Measurements - PS Analytical Sir Galahad ......... 12

3.6 Ontario Hydro Mercury Measurement Results $\ldots \ldots \ldots \ldots \ldots \ldots \ldots \ldots \ldots$

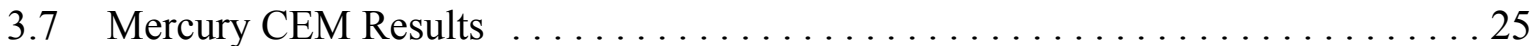

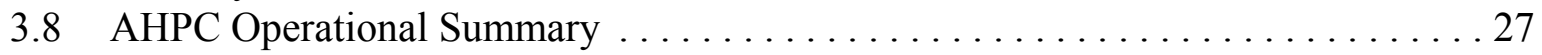

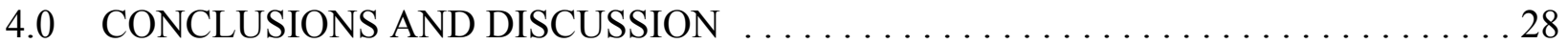




\section{LIST OF FIGURES}

1 Overview of carbon injection system $\ldots \ldots \ldots \ldots \ldots \ldots \ldots \ldots \ldots \ldots \ldots \ldots$

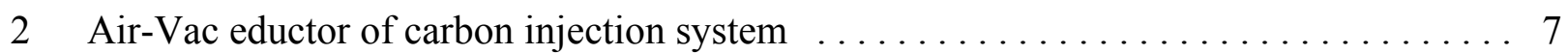

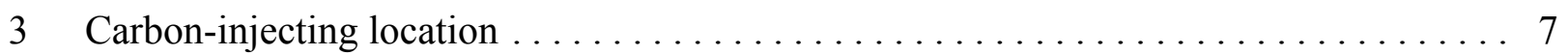

4 Schematic of mercury speciation sample train $\ldots \ldots \ldots \ldots \ldots \ldots \ldots \ldots \ldots \ldots \ldots \ldots$

5 Sample recovery scheme for the mercury speciation sampling train $\ldots \ldots \ldots \ldots \ldots 11$

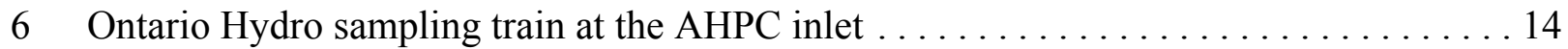

7 Ontario Hydro sampling at the AHPC outlet $\ldots \ldots \ldots \ldots \ldots \ldots \ldots \ldots \ldots \ldots \ldots \ldots \ldots \ldots \ldots$

8 Day $1-$ mercury species concentration in flue gas across the AHPC $\ldots \ldots \ldots \ldots \ldots 17$

9 Day 1 - percentage of mercury species distribution in flue gas across the AHPC . . . 17

10 Day 1 - mercury species collection efficiency in AHPC mode $\ldots \ldots \ldots \ldots \ldots \ldots \ldots$

11 Day 2 - mercury species concentration in flue gas across the AHPC unit in AHPC mode ........................................... 18

12 Day 2 - mercury species collection efficiency in AHPC mode .................. 19

13 Day 3 - mercury species concentration in flue gas across the AHPC unit in

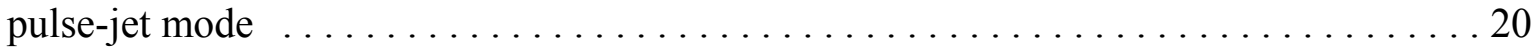

14 Day 3 - mercury species collection efficiency in pulse-jet mode $\ldots \ldots \ldots \ldots \ldots \ldots 20$

15 Day 4 - mercury species concentration in flue gas across the AHPC unit in

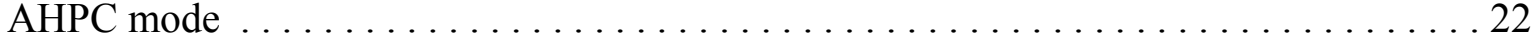

16 Day 4 - mercury species collection efficiency in AHPC mode $\ldots \ldots \ldots \ldots \ldots \ldots 22$

17 Day 5 - mercury species concentration in flue gas across the AHPC unit at Big Stone in both AHPC and pulse-jet mode .............................. 23

18 Day 5 - mercury species collection efficiency under AHPC and pulse-jet mode . . . . . 23

Continued... 


\section{LIST OF FIGURES (continued)}

19 Conversion system CEM mercury sampling $\ldots \ldots \ldots \ldots \ldots \ldots \ldots \ldots \ldots \ldots$

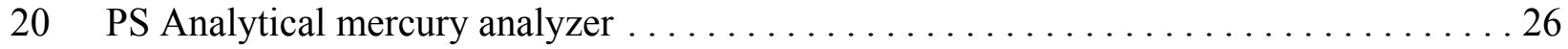

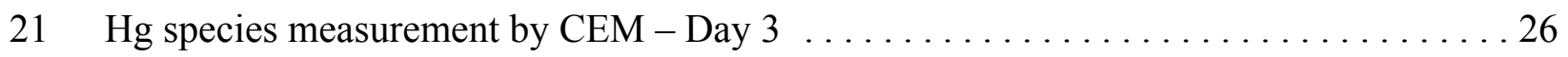

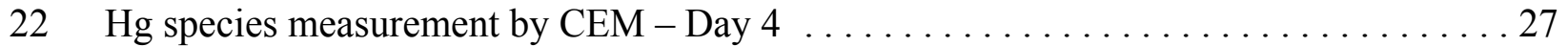

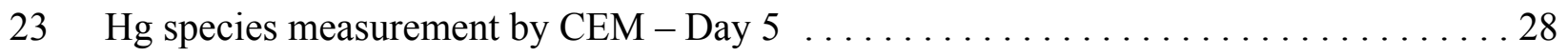




\section{LIST OF TABLES}

1 Summary of Mercury, Gas, and Solids Samples Taken . . . . . . . . . . . . . 4

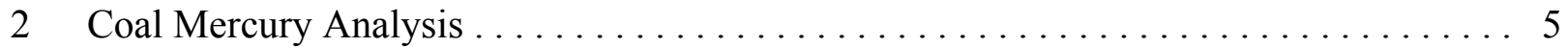

3 Coal Analysis for the Big Stone Power Plant $\ldots \ldots \ldots \ldots \ldots \ldots \ldots$

4 Summary of the Flue Gas Compositions During the 5-day Sampling . . . . . . . . . 8

5 Summary of the Flue Gas Compositions During the 5-Day Sampling $\ldots \ldots \ldots \ldots$

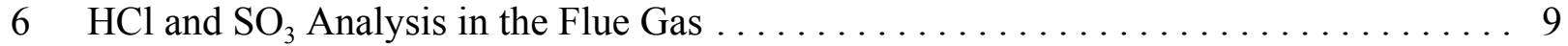

7 Sample Train Components - EPA Method 17 Configuration . . . . . . . . . . . . 10

8 Dust Loading at the AHPC Inlet and Outlet and the Calculated Collection Efficiency . . 15

9 Summary of Ontario Hydro Mercury Results $\ldots \ldots \ldots \ldots \ldots \ldots \ldots \ldots \ldots \ldots \ldots \ldots \ldots \ldots$

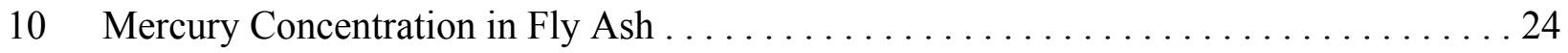




\section{LIST OF ACRONYMS}

$\begin{array}{ll}\text { AF } & \text { atomic fluorescence } \\ \text { AHPC } & \text { advanced hybrid particulate collector } \\ \text { A/C } & \text { air-to-cloth } \\ \text { BCI } & \text { bag-cleaning interval } \\ \text { CEM } & \text { continuous emission monitor } \\ \text { CVAAS cold-vapor atomic absorption spectroscopy } \\ \text { DOE } & \text { Department of Energy } \\ \text { EERC } & \text { Energy \& Environmental Research Center } \\ \text { EPA } & \text { Environmental Protection Agency } \\ \text { ESP } & \text { electrostatic precipitator } \\ \text { FGD } & \text { flue gas desulfurization } \\ \text { LOI } & \text { loss on ignition } \\ \text { PRB } & \text { Powder River Basin } \\ \text { PTC } & \text { particulate test combustor } \\ \text { SG } & \text { Smith Greenburg }\end{array}$




\section{MERCURY CONTROL WITH THE ADVANCED HYBRID PARTICULATE COLLECTOR}

\section{EXECUTIVE SUMMARY}

Since 1995, the U.S. Department of Energy (DOE) has supported development of a new concept in particulate control, called the advanced hybrid particulate collector (AHPC). The AHPC combines the best features of electrostatic precipitators (ESPs) and baghouses in a unique configuration, providing major synergism between the two collection methods, both in the particulate collection step and in the transfer of dust to the hopper.

The objective of this project is to demonstrate $90 \%$ total mercury control with commercially available sorbents in the AHPC at a lower cost than current mercury control estimates. The approach includes three levels of testing: 1) bench-scale batch testing that ties the new work to previous results and links results with larger-scale pilot testing with real flue gas on a coal-fired combustion system, 2) pilot-scale testing on a previously proven combustion system with both a pulse-jet baghouse and an AHPC to prove or disprove the research hypotheses, and 3) field demonstration pilot-scale testing at a utility power plant to prove scaleup and demonstrate longer-term mercury control.

During the first quarter of the project, initial bench-scale testing was completed, and plans were made for an initial field test earlier than planned in the original schedule.

The bench-scale results were in good agreement with previous data. This means that the planned work based on the previous results is still valid and that no changes to the overall experimental approach are necessary at this time.

Results show that the $\mathrm{SO}_{2}$ and $\mathrm{NO}_{2}$ concentration effects are additive and have a significant effect on sorbent performance. This finding should facilitate predicting sorbent performance in real systems when the $\mathrm{SO}_{2}$ and $\mathrm{NO}_{2}$ concentrations are known.

Testing with the 2.5-MW AHPC at Big Stone was not scheduled to begin until early 2002 after completing the first pilot-scale tests. However, the project team decided to complete an initial field test the first week of November 2001 prior to the pilot-scale tests at the EERC. By doing initial testing in November, mercury sampling in the worst part of the winter could be avoided. The plan is that mercury control testing at Big Stone will then resume in the spring of 2002 , and the completion of the field testing within the planned schedule is expected.

Results from the initial field test with the Big Stone AHPC showed that:

- The average inlet mercury speciation for seven samples was $55.4 \%$ particulate bound, $38.1 \%$ oxidized, and $6.4 \%$ elemental. The high level of particulate-bound mercury and oxidized mercury was somewhat surprising because for western PRB coals lower levels of particulate-bound mercury and oxidized mercury are more typical. However, significant capture of mercury by the fly ash has been observed in previous EERC pilot 
tests as well as a number of coal-fired plants burning western fuels. Possible factors that determine the level of particulate-bound and oxidized mercury include coal type, boiler type, $\mathrm{HCl}$ (as well as other flue gases), temperature, and amount of carbon in the fly ash. The current level of understanding of how these factors work together is insufficient to explain the observed mercury speciation for individual plants.

- A carbon injection rate of $1.5 \mathrm{lb} /$ million acf corresponds to a carbon-to-mercury ratio of approximately 2500 for the measured inlet mercury. With this carbon injection rate, from $91 \%$ to $97 \%$ total mercury collection efficiency was achieved, compared to $49 \%$ removal for the baseline case. Even though the carbon addition rate was low, the carbon was highly effective at removing mercury. The data show that the carbon was effective at removing both elemental and oxidized mercury.

- These short-term tests are highly encouraging because they prove that excellent mercury removal can be achieved with very low addition rates of carbon injected upstream of the AHPC. Further testing is needed to demonstrate that the high level of mercury removal can be maintained over the longer term and that the carbon injection will not have any adverse effect on the longer-term operation of the AHPC. 


\section{MERCURY CONTROL WITH THE ADVANCED HYBRID PARTICULATE COLLECTOR}

\subsection{INTRODUCTION}

This project was awarded under U.S. Department of Energy (DOE) Program Solicitation DE-PS26-00NT40769 and specifically addresses Technical Topic Area 4 - Testing Novel and Less Mature Control Technologies on Actual Flue Gas at the Pilot Scale. The project team includes the Energy \& Environmental Research Center (EERC) as the main contractor; W.L. Gore \& Associates, Inc., as a technical and financial partner; and the Big Stone Power Plant operated by Otter Tail Power Company, which will host the field testing portion of the research.

Since 1995, DOE has supported development of a new concept in particulate control, called the advanced hybrid particulate collector (AHPC). The AHPC combines the best features of electrostatic precipitators (ESPs) and baghouses in a unique configuration, providing major synergism between the two collection methods, both in the particulate collection step and in the transfer of dust to the hopper. The AHPC provides ultrahigh collection efficiency, overcoming the problem of excessive fine-particle emission with conventional ESPs, and it solves the problem of reentrainment and re-collection of dust in conventional baghouses. In Phase II of the DOE-funded AHPC project, a 2.5-MW-scale AHPC was designed, constructed, installed, and tested at the Big Stone Power Plant. For Phase III, further testing of an improved version of the 2.5-MW-scale AHPC at the Big Stone Power Plant was conducted to facilitate commercialization of the AHPC technology. The AHPC appears to have unique advantages for mercury control over baghouses or ESPs as an excellent gas-solid contactor.

The objective of this project is to demonstrate $90 \%$ total mercury control with commercially available sorbents in the AHPC at a lower cost than current mercury control estimates. The approach includes three levels of testing: 1) bench-scale batch testing that ties the new work to previous results and links results with larger-scale pilot testing with real flue gas on a coal-fired combustion system, 2) pilot-scale testing on a previously proven combustion system with both a pulse-jet baghouse and an AHPC to prove or disprove the research hypotheses, and 3) field demonstration pilot-scale testing at a utility power plant to prove scaleup and demonstrate longer-term mercury control.

\subsection{EXPERIMENTAL}

\subsection{Objective and Goals}

The overall project objective is to demonstrate $90 \%$ total mercury control with commercially available sorbents in the AHPC at a lower cost than current mercury control estimates. 
Test goals include the following:

- Determine if the bench-scale mercury breakthrough results can be duplicated when real flue gas is sampled.

- Compare the level of mercury control with sorbents under similar conditions at the $55-\mathrm{kW}$ pilot scale between the AHPC and a pulse-jet baghouse.

- Demonstrate $90 \%$ mercury capture for both a western subbituminous and an eastern bituminous coal.

- Demonstrate mercury capture with the 2.5-MW AHPC at Big Stone.

- Demonstrate $90 \%$ mercury capture over a longer time (3 months) with the 2.5 -MW $\mathrm{AHPC}$ at Big Stone.

\subsection{Planned Scope of Work}

To meet the objectives, the work was organized into five tasks:

- Task 1: Project Management, Reporting, and Technology Transfer

- Task 2: Bench-Scale Batch Testing

- Task 3: Pilot-Scale Testing

- Task 4: Field Demonstration Pilot Testing

- Task 5: Facility Removal and Disposition

\subsection{Initial Field Test with a 2.5-MW AHPC at the Big Stone Power Plant}

According to the planned work, testing with the 2.5-MW AHPC at Big Stone Power Plant was not scheduled to begin until early 2002 after completing the first pilot-scale tests. However, the project team decided to conduct an initial field test the first week of November 2001 prior to the pilot-scale tests at the EERC. There were several reasons for performing an initial early test:

- Delay in implementing the overall program by five months resulted in moving the whole schedule back by five months. With the original proposed work, the field testing would have begun in the summer. This would have prevented some of the weather problems associated with mercury sampling outside in the winter. By doing initial testing in November, we avoided having to begin the mercury sampling in the worst part of the winter. It is expected that the mercury control testing at Big Stone will then resume in the spring of 2002, and the completion of the field testing within the planned schedule should still be possible.

- A full-scale retrofit of an AHPC at Big Stone was recently announced by DOE as one of the projects selected under the DOE Power Plant Improvement Initiative. Because design of this project must begin immediately, it is imperative to have as much information available as possible. By completing this initial field test early, additional 
information on AHPC performance with carbon injection should facilitate final design of the full-scale Big Stone AHPC.

- Since no mercury sampling has previously been completed at the Big Stone Power Plant, early baseline data on the actual inlet mercury concentration and speciation should help in finalizing the EERC pilot plant testing. For example, if higher-thanexpected fly ash capture of mercury were seen at Big Stone, that would have to be considered in planning the pilot plant tests.

The field test at Big Stone was completed the week of November 5-10, 2001, with baseline testing on the first day, followed by carbon injection in both AHPC and pulse-jet operational modes for the remainder of the week. The starting carbon addition rate was set at $24 \mathrm{~kg}$ of carbon sorbent/million $\mathrm{m}^{3}$ of flue gas $(1.5 \mathrm{lb}$ of carbon sorbent/million acf), with the plan that it could be increased if necessary to achieve good mercury control. However, over $90 \%$ mercury control was seen at this carbon addition rate so no testing was completed at higher carbon concentrations.

A total of four Ontario Hydro mercury measurement samples were taken for each day, including both at the inlet and outlet of the AHPC. Two mercury continuous emission monitors (CEMs) provided additional information on the inlet and outlet mercury concentrations during the last three days of testing.

The first day was a baseline test in AHPC mode with no carbon injection where the AHPC was held at a constant $\mathrm{A} / \mathrm{C}$ ratio of $3.0 \mathrm{~m} / \mathrm{min}(10 \mathrm{ft} / \mathrm{min})$, the bags were cleaned on a constant timed 20-min interval, and the ash hopper was emptied once per hour.

For the second day, conditions were identical except for carbon addition at a rate of $24 \mathrm{~kg}$ of carbon sorbent/million $\mathrm{m}^{3}$ (1.5 lb of carbon sorbent/million acf). The DARCO FGD carbon used was obtained from Norit Americas and is commercially available. The carbon addition was controlled with a K-Tron powder feeder and was injected pneumatically at a single point into the center of the $0.610 \mathrm{~m}$ (24-in)-diameter inlet duct.

For the third day, the AHPC was operated with carbon injection as a pulse-jet baghouse at an air-to-cloth $(\mathrm{A} / \mathrm{C})$ ratio of $1.5 \mathrm{~m} / \mathrm{min}(5 \mathrm{ft} / \mathrm{min})$, or one half the flow rate of the previous two days. To keep the same carbon-to-flue gas ratio of $24 \mathrm{~kg}$ of carbon sorbent/million $\mathrm{m}^{3}(1.5 \mathrm{lb}$ of carbon sorbent/million acf), the carbon feed rate was set to half the previous level.

The fourth day was a repeat of Day 2 where the unit was again operated in AHPC mode with carbon injection at $24 \mathrm{~kg}$ of carbon sorbent $/$ million $\mathrm{m}^{3}(1.5 \mathrm{lb}$ of carbon sorbent/million acf).

For the fifth day of testing the unit was operated with carbon injection in both AHPC and pulse-jet modes, but with both at an $\mathrm{A} / \mathrm{C}$ ratio of $1.5 \mathrm{~m} / \mathrm{min}(5 \mathrm{ft} / \mathrm{min})$. This test was completed to allow for a valid comparison between the AHPC and pulse-jet modes without changing the residence time or temperature. 
For all of the tests with carbon, the sorbent was injected only during the day, and after completing the mercury sampling, the carbon was shut off overnight to allow the unit to return to baseline conditions prior to starting carbon injection the next day.

A summary of the mercury, solids, and flue gas sampling is given in Table 1.

Table 1. Summary of Mercury, Gas, and Solids Samples Taken

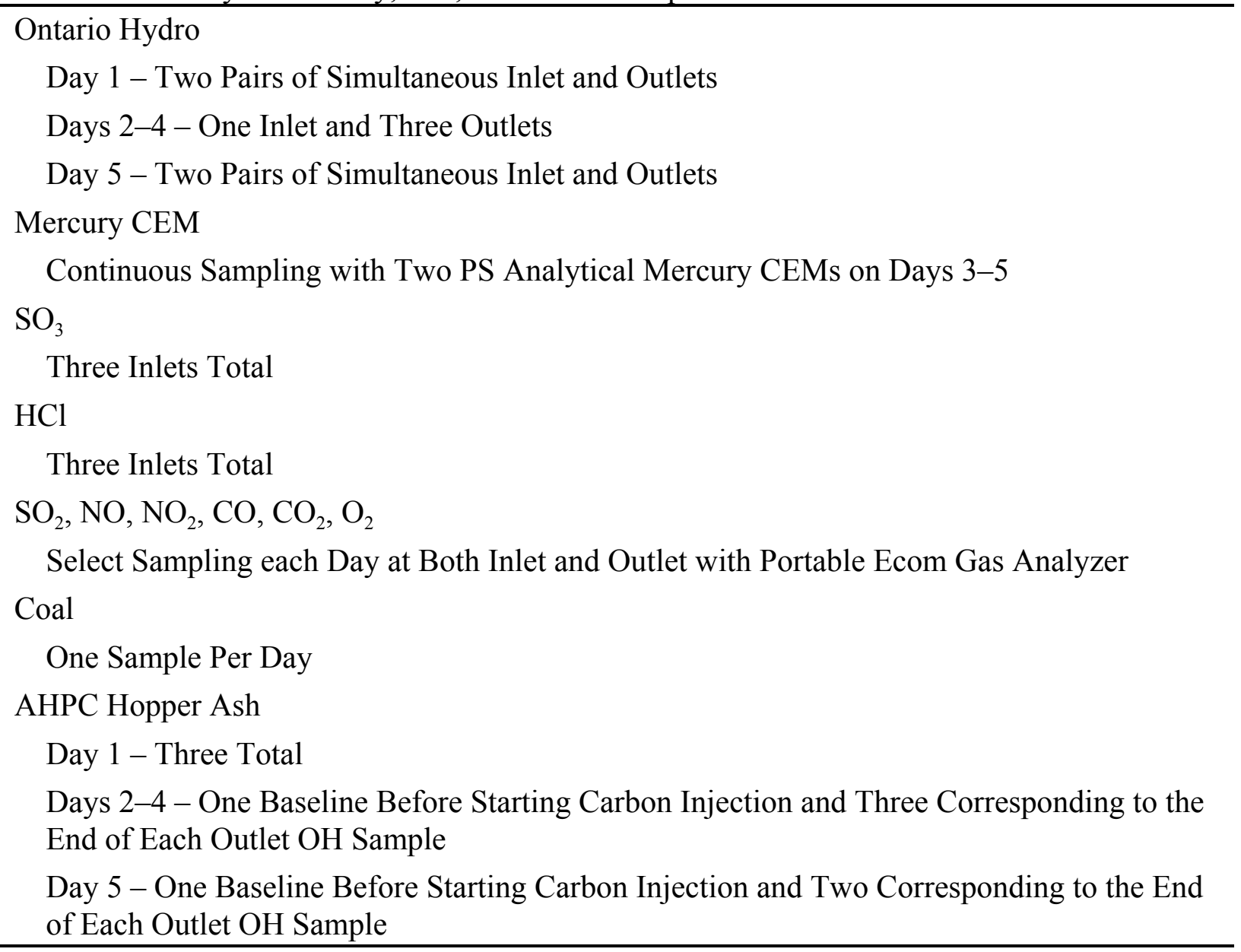

\subsection{RESULTS AND DISCUSSIONS}

\subsection{Coal Sampling and Analysis}

A 4 L (1-gallon) grab sample of coal was collected each day from the coal feed conveyor by Big Stone Power Plant personnel. Since some supplementary corn was also being burned, the coal sample was screened to remove the corn and then analyzed for mercury. The mercury analysis for the five coal samples is shown in Table 2 to have a mean value of $0.126 \mu \mathrm{g} / \mathrm{g}$, while a single analysis of the corn indicates almost no mercury originated from the corn. Ultimate and proximate analysis for the coal sample from Day 5 is shown in Table 3. 
Table 2. Coal Mercury Analysis

\begin{tabular}{lc}
\hline Sample & Hg Concentration, dry coal basis, $\mu \mathrm{g} / \mathrm{g}$ \\
\hline Day 1 & 0.127 \\
Day 2 & 0.122 \\
Day 3 & 0.105 \\
Day 4 & 0.149 \\
Day 5 & 0.125 \\
Mean & 0.126 \\
Corn Screened from Feed Coal & $<0.001$ \\
\hline
\end{tabular}

Table 3. Coal Analysis for the Big Stone Power Plant

\begin{tabular}{lcc}
\hline Proximate Analysis & \% As Sampled & \% Moisture Free \\
\hline Moisture Content & 29.3 & NA \\
Volatile Matter & 33.92 & 47.96 \\
Fixed Carbon & 31.57 & 44.67 \\
Ash & 5.21 & 7.37 \\
\hline Ultimate Analysis & & \\
\hline Hydrogen & 6.48 & 4.57 \\
Carbon & 49.46 & 69.93 \\
Nitrogen & 0.77 & 1.09 \\
Sulfur & 0.38 & 0.54 \\
Oxygen & 37.69 & 16.50 \\
Ash & 5.21 & 7.37 \\
Heating Value, Btu/lb & 8607 & 12174 \\
\hline
\end{tabular}

\subsection{Coal Combustion Calculation}

From the ultimate analysis, a theoretical combustion calculation was completed to determine the theoretical mercury concentration in the inlet flue gas. From the combustion calculation, the coal should produce $5.89 \mathrm{~m}^{3}$ of dry flue gas per $\mathrm{kg}(94.3 \mathrm{scf}$ of dry flue gas per lb) of coal normalized to $3.0 \%$ oxygen, which corresponds to a theoretical inlet mercury concentration of $15.1 \mu \mathrm{g} / \mathrm{Nm}^{3}$ of dry flue gas at $3.0 \% \mathrm{O}_{2}$. The theoretical inlet mercury value is somewhat higher than the 11.0 to $13.3 \mu \mathrm{g} / \mathrm{Nm}^{3}$ inlet total mercury concentrations measured by the Ontario Hydro method. Possible reasons for the difference are discussed later in this report. 


\subsection{Carbon Injection}

The DARCO FGD activated carbon is a commercially available sorbent produced by Norit Americas. DARCO FGD powdered activated carbon is a lignite coal-base activated carbon manufactured specifically for the removal of heavy metals and other contaminants typically found in incinerator flue gas emission streams. It has a surface area of $600 \mathrm{~m}^{2} / \mathrm{g}$ and has been proven in numerous full-scale operating facilities to be highly effective for the removal of gaseous mercury, dioxins (PCDD) and furans (PCDF). Its open pore structure and fine-particle size permit rapid adsorption, which is critical for high performance in flue gas streams where contact times are short.

DARCO FGD is a fine-flowing powdered carbon with minimal caking tendencies, which makes it ideal for automatic dosing systems with dry or wet injection. It is manufactured with a very high ignition temperature to permit safe operation at the elevated temperatures inherent in incinerator flue gas streams. This is a carbon that has been previously investigated by the EERC and other researchers for mercury control from coal-fired boilers.

The carbon was fed with a K-Tron dual-screw feeder at a rate of $24 \mathrm{~kg}$ of carbon sorbent/million $\mathrm{m}^{3}$ (1.5 lb of carbon sorbent/million acf), which corresponds to $0.29 \mathrm{~kg} / \mathrm{hr}$ $(0.65 \mathrm{lb} / \mathrm{hr})$ at an $\mathrm{A} / \mathrm{C}$ ratio of $3.0 \mathrm{~m} / \mathrm{min}(10 \mathrm{ft} / \mathrm{min})$ and $0.15 \mathrm{~kg} / \mathrm{hr}(0.325 \mathrm{lb} / \mathrm{hr})$ at an $\mathrm{A} / \mathrm{C}$ ratio of $1.5 \mathrm{~m} / \mathrm{min}(5 \mathrm{ft} / \mathrm{min})$. The carbon feeder was located in the enclosed area of the AHPC below the hopper (Figures 1 and 2). From the screw feeder, the carbon was introduced into an Air-Vac eductor that was driven by compressed air. From the outlet of the eductor, the carbon was then transported approximately $6.1 \mathrm{~m}(20 \mathrm{ft})$ through $0.019-\mathrm{m}(0.75-\mathrm{in}$.) stainless steel tubing to the elbow location of the inlet piping (Figure 3).

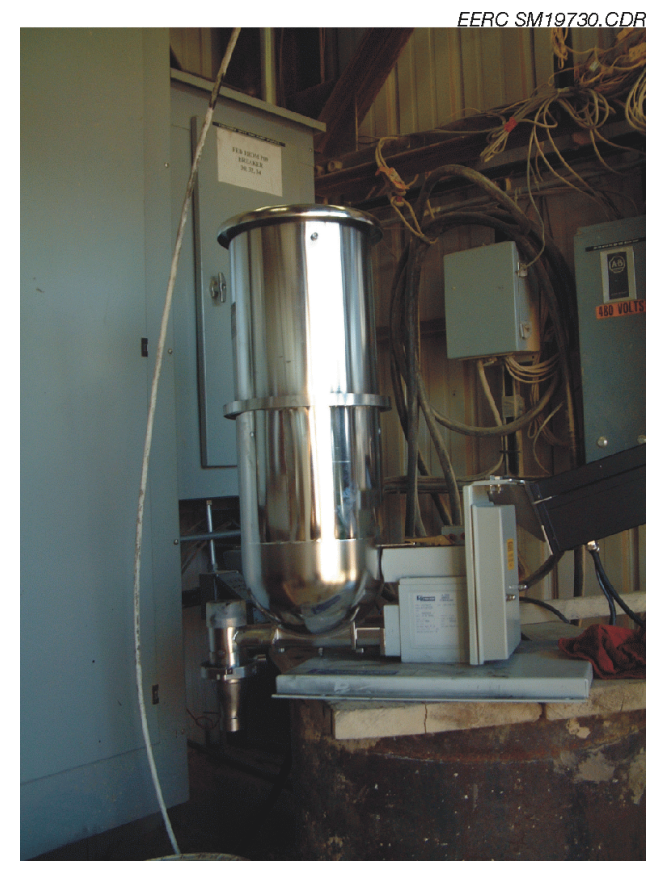

Figure 1. Overview of carbon injection system. 


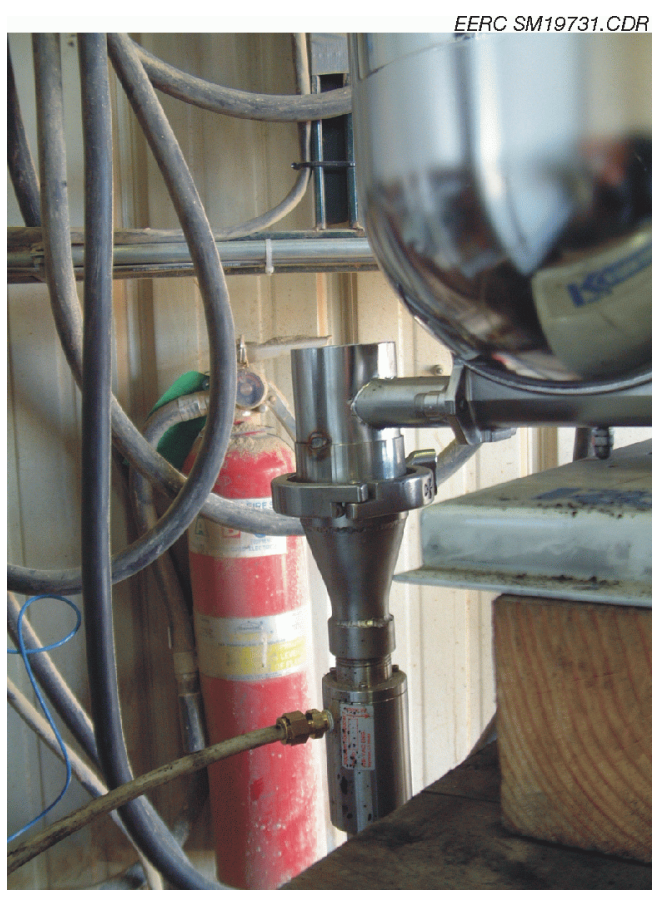

Figure 2. Air-Vac eductor of carbon injection system.

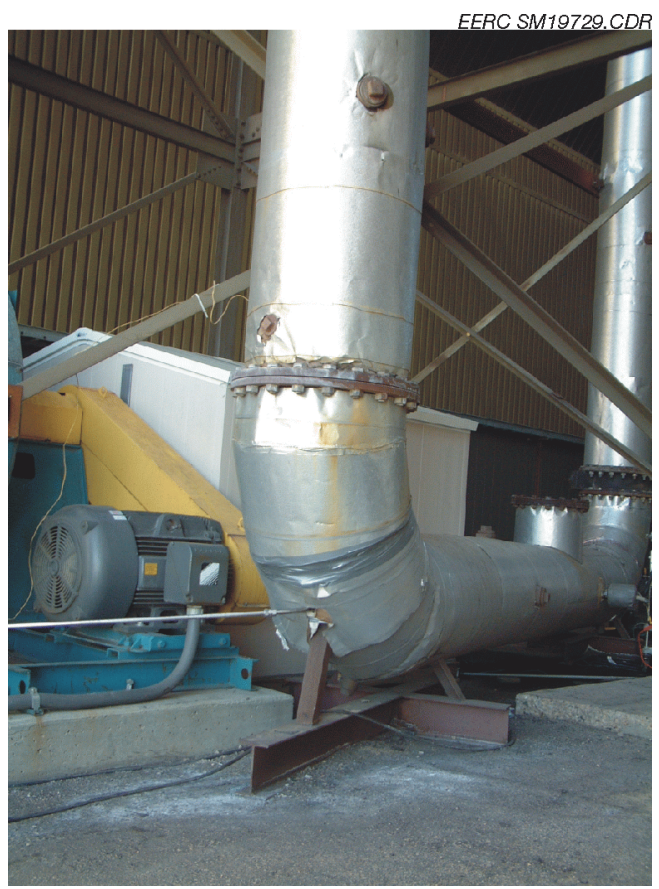

Figure 3. Carbon-injecting location. 


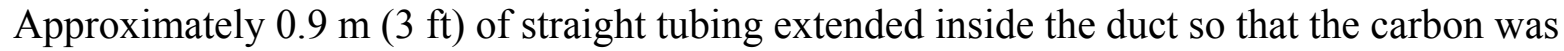
injected directly upstream at a single point in the center of the $0.610-\mathrm{m}$ (24-in.)-diameter inlet pipe.

The feeder was calibrated prior to the start of carbon injection and again at the end of each day. In addition, the weight of carbon added during a day was divided by the time of injection to provide an average feed rate. According to the calibration data and weight-of-added-carbon data, the feeder appeared to provide a very steady and consistent feed rate within a few percent of the target rate. The carbon feed and injection system worked very well, and there were no problems with inconsistent feeding or plugging of the feeder or injection system.

\subsection{Flue Gas Composition}

Flue gas composition was measured each day both at the AHPC inlet and outlet by using a portable Ecom gas analyzer which provided the concentrations of $\mathrm{O}_{2}, \mathrm{CO}_{2}, \mathrm{CO}, \mathrm{NO}, \mathrm{NO}_{2}$, and $\mathrm{SO}_{2}$ in the flue gas on a dry basis. The results for the 5-day sampling are listed in Table 4 . Because of the use of low-sulfur coal of the Cordero Rojo complex, the $\mathrm{SO}_{2}$ concentration in the flue gas was low, ranging from 165 to $299 \mathrm{ppm}$. The $\mathrm{NO}$ and $\mathrm{NO}_{2}$ concentrations in the flue gas were $499-575 \mathrm{ppm}$ for $\mathrm{NO}$ and only $1-4 \mathrm{ppm}$ for $\mathrm{NO}_{2}$. Gas concentrations normalized to a $3 \%$ $\mathrm{O}_{2}$ level are shown in Table 5. Three $\mathrm{SO}_{3}$ samples (by using selective condensation method) and three $\mathrm{HCl}$ samples (using U.S. Environmental Protection Agency [EPA] Method 26) were collected at the AHPC inlet during the 5-day test. The samples were analyzed and the results were normalized to $3 \% \mathrm{O}_{2}$ dry flue gas, as shown in Table 6 .

Table 4. Summary of the Flue Gas Compositions During the 5-day Sampling (dry basis)

\begin{tabular}{lccccccc}
\hline & & $\mathrm{O}_{2}, \%$ & $\mathrm{CO}_{2}, \%$ & $\mathrm{CO}, \mathrm{ppm}$ & $\mathrm{NO}, \mathrm{ppm}$ & $\mathrm{NO}_{2}, \mathrm{ppm}$ & $\mathrm{SO}_{2}, \mathrm{ppm}$ \\
\hline \multirow{2}{*}{ Day 1} & In & 6.2 & 13.1 & 1 & 509 & 4 & 165 \\
& Out & 5.1 & 14.1 & 1 & 543 & 3 & 238 \\
\hline \multirow{2}{*}{ Day 2 } & In & 4.9 & 14.3 & $!$ & 545 & 2 & 252 \\
& Out & 5.0 & 14.2 & 10 & 531 & 2 & 247 \\
\hline \multirow{2}{*}{ Day 3 } & In & 5.3 & 13.9 & 2 & 575 & 2 & 251 \\
& Out & 5.3 & 13.9 & 1 & 514 & 3 & 248 \\
\hline \multirow{2}{*}{ Day 4 } & In & 5.2 & $!$ & $!$ & 545 & 2 & 260 \\
& Out & 5.3 & $!$ & 4 & 499 & 1 & 299 \\
\hline \multirow{2}{*}{ Day 5 } & In & 5.1 & 14.1 & 2 & 541 & 2 & 226 \\
& Out & 5.5 & 13.8 & 1 & 523 & 3 & 201 \\
\hline
\end{tabular}


Table 5. Summary of the Flue Gas Compositions During the 5-Day Sampling (dry basis normalized to $3 \% \mathrm{O}_{2}$ )

\begin{tabular}{lccccccc}
\hline & & $\mathrm{O}_{2}, \%$ & $\mathrm{CO}_{2}, \%$ & $\mathrm{CO}, \mathrm{ppm}$ & $\mathrm{NO}, \mathrm{ppm}$ & $\mathrm{NO}_{2}, \mathrm{ppm}$ & $\mathrm{SO}_{2}, \mathrm{ppm}$ \\
\hline \multirow{2}{*}{ Day 1 } & In & 3.0 & 15.9 & 1.2 & 619.0 & 4.9 & 201 \\
& Out & 3.0 & 16.0 & 1.1 & 614.7 & 3.4 & 269 \\
\hline \multirow{2}{*}{ Day 2 } & In & 3.0 & 16.0 & $!$ & 609.3 & 2.2 & 282 \\
& Out & 3.0 & 16.0 & 11 & 597.4 & 2.2 & 278 \\
\hline \multirow{2}{*}{ Day 3 } & In & 3.0 & 16.0 & 2.3 & 659.2 & 2.3 & 288 \\
& Out & 3.0 & 16.0 & 1.1 & 589.3 & 3.4 & 284 \\
\hline \multirow{2}{*}{ Day 4 } & In & 3.0 & $!$ & $!$ & 620.9 & 2.3 & 296 \\
& Out & 3.0 & $!$ & 4.6 & 572.1 & 1.1 & 343 \\
\hline \multirow{2}{*}{ Day 5 } & In & 3.0 & 16.0 & 2.3 & 612.4 & 2.3 & 256 \\
& Out & 3.0 & 16.0 & 1.2 & 607.4 & 3.5 & 233 \\
\hline
\end{tabular}

Table 6. $\mathrm{HCl}$ and $\mathrm{SO}_{3}$ Analysis in the Flue Gas, ppm dry at 3\% $\mathrm{O}_{2}$

\begin{tabular}{lccc}
\hline Gas & Sample 1 & Sample 2 & Sample 3 \\
\hline $\mathrm{HCl}$ & 9.12 & 10.12 & 9.95 \\
$\mathrm{SO}_{3}$ & 0.41 & 0.61 & 0.65 \\
\hline
\end{tabular}

\subsection{Mercury Sampling Procedures}

\subsubsection{Ontario Hydro Mercury Speciation Method}

For this method, a sample is withdrawn from the flue gas stream isokinetically through the filtration system, which is followed by a series of impingers in an ice bath. A schematic of the sample train is shown in Figure 4, and Table 7 presents a list of sample train components. Particulate-bound mercury is collected on the front half and filter; oxidized mercury is collected in impingers containing $1 \mathrm{~N}$ potassium chloride solution; and elemental mercury is collected in one impinger containing a 5\% nitric acid and $10 \%$ peroxide solution and in three impingers containing a solution of $10 \%$ sulfuric acid and $4 \%$ potassium permanganate. An impinger containing silica gel collects any remaining moisture. Quartz fiber filters were used as the filter media for the testing, and the filter holder was glass. A heated Teflon line was used between the probe and impinger train.

Figure 5 is a schematic of the sample recovery procedure for the impinger train. The samples were recovered into precleaned glass bottles with vented Teflon-lined lids for submission to the laboratory. The following sample fractions were recovered (specific rinse solutions are contained in the method):

- Container 1 - sample filter

- Container 2 - front-half rinse (includes all surfaces upstream of the filter) 


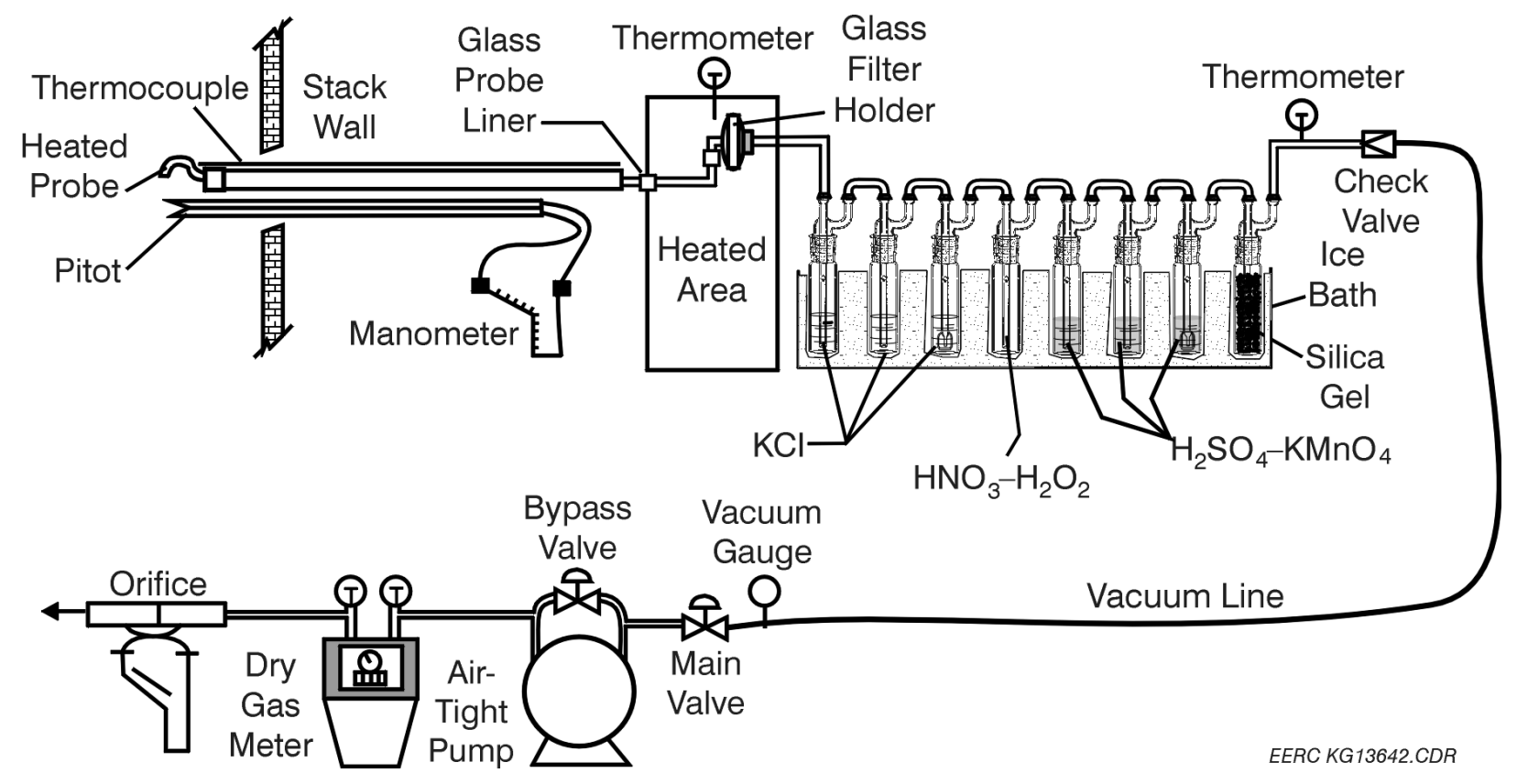

Figure 4. Schematic of mercury speciation sample train.

Table 7. Sample Train Components - EPA Method 17 Configuration

\begin{tabular}{ll}
\hline Component & \multicolumn{1}{c}{ Details } \\
\hline Nozzle & Quartz \\
Filter & Quartz in glass \\
Probe & Quartz heated to a minimum temperature of 120EC (338EF) \\
Connector Line & $\begin{array}{l}\text { Teflon line used to connect from probe to impingers - heated to a } \\
\text { minimum of 120EC (338EF) }\end{array}$ \\
Impingers 1 and 2 & $1 \mathrm{~N} \mathrm{KCl} \mathrm{solution;} \mathrm{modified} \mathrm{Smith} \mathrm{Greenburg} \mathrm{(SG)} \mathrm{impinger}$ \\
Impinger 3 & $1 \mathrm{~N} \mathrm{KCl} \mathrm{solution;} \mathrm{standard} \mathrm{SG} \mathrm{impinger}$ \\
Impinger 4 & $5 \%$ nitric acid-10\% hydrogen peroxide; modified SG impinger \\
Impingers 5 and 6 & $\begin{array}{l}10 \% \text { sulfuric acid-4\% potassium permanganate; modified SG impinger } \\
\text { Impinger 7 }\end{array}$ \\
Impinger 8 & Silica gel; modified SG impinger
\end{tabular}

- Container 3 - Impingers 1 through 3 ( $\mathrm{KCl}$ impingers) and rinses

- Container 4 - Impinger $4\left(\mathrm{HNO}_{3}-\mathrm{H}_{2} \mathrm{O}_{2}\right.$ impinger $)$ and rinses

- Container 5 - Impingers 5 through $7\left(\mathrm{H}_{2} \mathrm{SO}_{4}-\mathrm{KMnO}_{4}\right.$ impingers $)$ and rinse

- Silica Gel-Impinger 8 (silica gel impinger) (note that this sample is weighed for moisture determination and is not included in the mercury analysis) 
1. Rinse filter holder and connector with $0.1 \mathrm{~N} \mathrm{HNO}_{3}$.

2. Add $5 \% \mathrm{w} / \mathrm{v} \mathrm{KMnO}_{4}$ to each impinger bottle until purple color remains.

3. Rinse with $10 \% \mathrm{v} / \mathrm{v} \mathrm{HNO}_{3}$.

4. Rinse with a very small amount of $10 \% \mathrm{w} / \mathrm{v}$ $\mathrm{NH}_{2} \mathrm{OH} \cdot \mathrm{H}_{2} \mathrm{SO}_{4}$ if brown residue remains.

5. Final rinse with $10 \% \mathrm{v} / \mathrm{vNO}$.
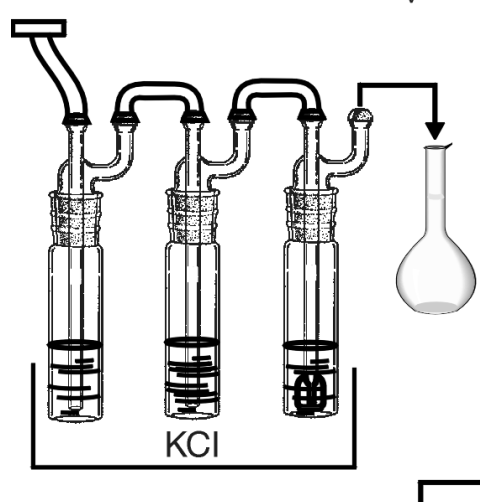

Rinse with $0.1 \mathrm{~N} \mathrm{HNO}_{3}-0.1 \mathrm{~N} \mathrm{HNO}_{3}$

Rinse Bottles Sparingly with

$-0.1 \mathrm{~N} \mathrm{HNO}_{3}$

$-10 \% \mathrm{w} / \mathrm{v} \mathrm{NH}_{2} \mathrm{OH} \cdot \mathrm{H}_{2} \mathrm{SO}_{4}$

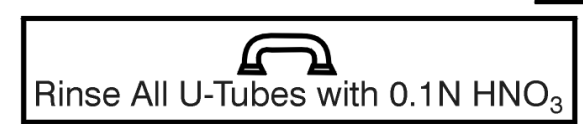

EERC DL16139.CDR

Figure 5. Sample recovery scheme for the mercury speciation sampling train.

The sample fractions were prepared and analyzed as specified in the method and summarized below:

- Ash Sample (Containers 1 and 2) - The particulate catch was digested and analyzed using EPA Method 3051 with subsequent analysis using EPA Method 7471A.

- $\mathrm{KCl}$ Impingers (Container 3) - The impingers were prepared using $\mathrm{H}_{2} \mathrm{SO}_{4}, \mathrm{HNO}_{3}$, and $\mathrm{KMnO}_{4}$ solutions as specified in the method.

- $\mathrm{HNO}_{3}-\mathrm{H}_{2} \mathrm{O}_{2}$ (Container 4) - The impinger solution was prepared using $\mathrm{HCl}$ and $\mathrm{KMnO}_{4}$ solutions as specified in the method.

- $\mathrm{H}_{2} \mathrm{SO}_{4}-\mathrm{KMnO}_{4}$ Impingers (Container 5) - The impinger solution was prepared using hydroxylamine sulfate as specified in the method.

Each prepared fraction was analyzed for total mercury by cold-vapor atomic absorption (CVAAS). CVAAS is a method based on the absorption of radiation at $253.7 \mathrm{~nm}$ by mercury vapor. The mercury is reduced to the elemental state and aerated from solution in a closed system. The mercury vapor passes through a cell positioned in the light path of an atomic absorption spectrometer. Mercury concentration is proportional to the indicated absorbance. A soda-lime trap and a magnesium perchlorate trap were used to precondition the gas before it entered the absorption cell. 


\subsubsection{Mercury CEM Measurements - PS Analytical Sir Galahad}

The Sir Galahad analyzer can be used in a variety of gaseous media including combustion flue gas. The analyzer is based on the principle of atomic fluorescence (AF), which provides an inherently more sensitive signal than atomic absorption. The system uses a gold-impregnated silica support for preconcentrating the mercury and separating it from potential interferences that degrade sensitivity.

The Sir Galahad requires a four-step process to obtain a flue gas mercury measurement. In the first step, $2 \mathrm{~L}$ of flue gas is pumped through a gold trap which is maintained at a constant temperature. Before the mercury is desorbed from the gold trap, a flushing step is initiated to remove any flue gas that may be present because it has a damping effect on the mercury fluorescence. When this is completed, the analysis step begins. The heating coil is activated, and the gold trap is heated to approximately $500 \mathrm{EC}(932 \mathrm{EF})$. This desorbs the mercury from the trap, and the mercury is carried into the fluorescence detector. The gold trap is rapidly cooled by pumping argon over it, in preparation for the next sample. The total time for the entire process is about 5 minutes per sample.

The system was calibrated using $\mathrm{Hg}^{0}$ as the primary standard. The $\mathrm{Hg}^{0}$ is contained in a closed vial which is held in a thermostatic bath. The temperature of the mercury is monitored, and the amount of mercury is calculated using vapor pressure calculations. Typically, the calibration of the unit has proven stable over a 24 -hr period.

Whether the CEM uses CVAA or AF to measure mercury, some form of gas pretreatment is necessary before accurate measurement of total mercury (or speciated mercury) can be accomplished. For the CVAA-type systems, only $\mathrm{Hg}^{0}$ can be directly analyzed. Therefore, all mercury forms in the flue gas must be converted to $\mathrm{Hg}^{0}$.

For the AF CEMs, a pretreatment/conversion system is also needed, but for a different reason. Both $\mathrm{Hg}^{+}$and $\mathrm{Hg}^{0}$ collect on the gold trap; however, if $\mathrm{HCl}$ and $\mathrm{NO}_{2}$ are present in the flue gas, the gold trap is permanently poisoned. To prevent this, since the $\mathrm{HCl}$ is much easier to remove than $\mathrm{NO}_{2}$, the $\mathrm{HCl}$ is removed prior to the flue gas passing through the gold trap. Also, if the instrument is to be used to provide mercury speciation data, then the $\mathrm{Hg}^{+}$must be removed from the gas stream so that the $\mathrm{Hg}^{0}$ concentration can be measured.

For several years, the EERC has been working on the development of pretreatment/ conversion systems for both CVAA- and AF-type mercury CEMs. The system that is currently used by the EERC consists of three primary parts:

1. An acid gas trap that removes the $\mathrm{SO}_{2}$ and $\mathrm{HCl}$ without removing any of the mercury

2. A $\mathrm{SnCl}_{2}$ gas-liquid separator to convert all $\mathrm{Hg}^{+}$to $\mathrm{Hg}^{0}$

3. A gas-liquid separator that removes $\mathrm{Hg}^{+}$without removing $\mathrm{Hg}^{0}$

Depending on which side of the pretreatment system the flue gas is passed through, either only $\mathrm{Hg}^{0}$ or total mercury is measured. 


\subsection{Ontario Hydro Mercury Measurement Results}

Ontario Hydro sampling trains were set up at the AHPC inlet and outlet to measure mercury species concentrations in the flue gas. Figure 6 shows the inlet sampling location which

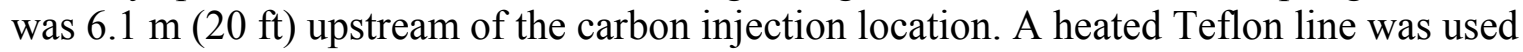
between the probe and impinger train. The target sampling time was 2 hours. The flue gas was isokinetically pulled through the filtration system to remove fly ash from flue gas. The particlefree flue gas then passed through a series of impingers to capture elemental and oxidized mercury followed by a silica gel-filled impinger where the moisture and $\mathrm{SO}_{2}$ were removed. The dry flue gas exiting the impinger was conveyed through a control module to measure the flow rate and the gas temperature. The outlet sampling location was just before the flue gas entered the fan, as shown in Figure 7. Since the Ontario Hydro method uses isokinetic sampling to measure mercury concentration in fly ash particles, it also provides information on dust loading in the flue gas. As shown in Figure 6, the inlet sampling location was around $1.5 \mathrm{~m}(5 \mathrm{ft})$ downstream of an elbow where flue gas had a 90 degree change of flow direction, which may result in a nonuniform fly ash distribution in the duct cross section. Some of the larger-sized fly ash particles may concentrate in the lower part of the dust because of their greater inertia, causing a lower dust- loading measurement than the real value in the system. A biased dustloading measurement may result in slight underestimations of both particle collection efficiency and total mercury capture efficiency.

The AHPC unit was operated at an A/C ratio of $3.0 \mathrm{~m} / \mathrm{min}(10 \mathrm{ft} / \mathrm{min})$ without carbon injection on the Day 1 test. Two pairs of simultaneous inlet and outlet Ontario Hydro samples were collected and sent back to the EERC the same day for mercury species analysis. The analysis data showed higher-than-expected mercury concentrations in the sampling solutions: $\mathrm{KCl}, \mathrm{H}_{2} \mathrm{O}_{2}$, and $\mathrm{KMnO}_{4}$. The field blank samples also demonstrated high mercury concentration, indicating contamination occurred. Not knowing the source of mercury contamination, the mercury-sampling tests were carried out on Day 2 (November 7, 2001) under AHPC mode with an $\mathrm{A} / \mathrm{C}$ ratio of $3.0 \mathrm{~m} / \mathrm{min}(10 \mathrm{ft} / \mathrm{min})$ and a carbon injection rate of $0.29 \mathrm{~kg} / \mathrm{hr}(0.65 \mathrm{lb} / \mathrm{hr})$ (corresponding to $24 \mathrm{~kg}$ of carbon/million $\mathrm{m}^{3}$ [1.5 lb carbon/million acf]). All the samples and chemical solutions used for recovering mercury were sent back to the EERC for mercury analysis and to look for the source of mercury contamination. Analysis data showed that the $10 \%$ nitric acid used for mercury recovery in sampling was contaminated, which resulted in the high mercury concentrations measured in the Ontario Hydro samples collected in Day 1 and 2 tests. A new batch of mercury-free $10 \%$ nitric acid was prepared and used for the following sampling tests. In order to validate the sampling results for Days 1 and 2, the mercury concentrations in the sampling solutions were subtracted by the measured mercury concentrations in the corresponding field blank impinger solutions, and the corrected data were reported as approximate mercury concentrations in the flue gas.

As discussed earlier, the Ontario Hydro sampling method provides mercury species information in flue gas as elemental mercury vapor, oxidized mercury, and mercury associated with particulate matter. All the results are presented in the form of $\mu \mathrm{g} / \mathrm{Nm}^{3}$ based on the CVAA analysis results of the impinger solutions, sampling flue gas volume, and dust loading. All of the measured mercury concentrations in the flue gas were corrected to a moisture-free $3 \% \mathrm{O}_{2}$ level to allow a valid comparison at varying $\mathrm{O}_{2}$ levels. 


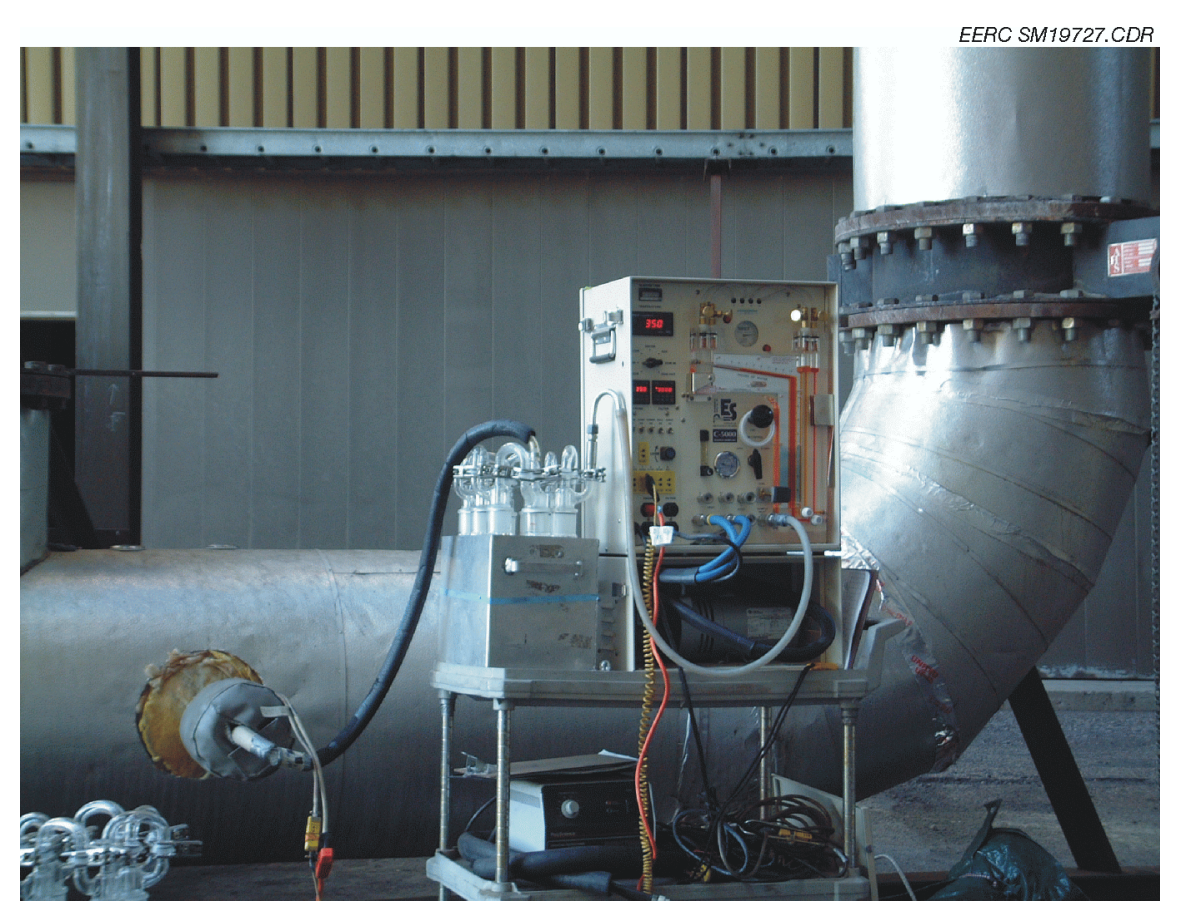

Figure 6. Ontario Hydro sampling train at the AHPC inlet.

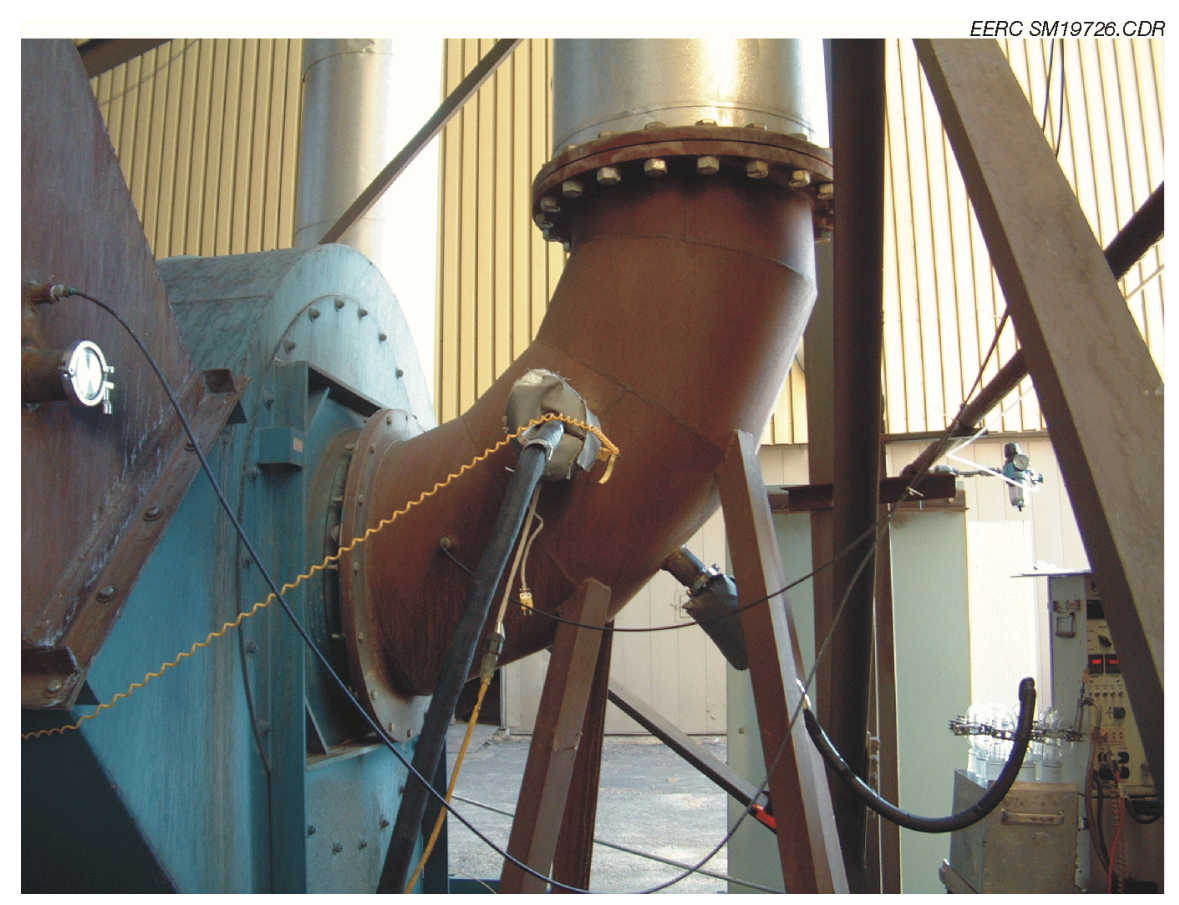

Figure 7. Ontario Hydro sampling at the AHPC outlet. 
The dust-loading measurement results at the inlet and outlet of the AHPC system (obtained from Ontario Hydro method) are listed in Table 8, and the corresponding particle collection efficiencies are also calculated and presented in Table 8 . The indicated particle collection efficiency ranged from $99.972 \%$ to $100 \%$, which represents the level of accuracy that can be achieved by this method with a 2-hr sample. Earlier tests on the Big Stone AHPC where the outlet was sampled for over 15 hours indicated dust loadings in the range of 0.00009 to $0.0002 \mathrm{gr} / \mathrm{m}^{3}$ (0.00004 to $\left.0.00009 \mathrm{gr} / \mathrm{dscf}\right)$. Independent measurements with real-time particle analyzers have also proven the collection efficiency to be better than $99.99 \%$.

Table 8. Dust Loading at the AHPC Inlet and Outlet and the Calculated Collection Efficiency

\begin{tabular}{lccc}
\hline & Inlet, gr/dscf & Outlet, gr/dscf & Collection Efficiency, \% \\
\hline Day 1-1 & 1.169 & 0.000250 & 99.978 \\
Day 1-2 & 1.235 & 0.000191 & 99.984 \\
Day 2-1 & 1.324 & 0.000363 & 99.972 \\
Day 3-1 & 0.909 & 0.000231 & 99.974 \\
Day 4-1 & 1.189 & $1.760 \mathrm{E}-06$ & 99.999 \\
Day 5-1 & 0.909 & 0 & 100.000 \\
Day 5-2 & 0.916 & $8.880 \mathrm{E}-05$ & 99.990 \\
\hline
\end{tabular}

A summary of mercury analysis results from the Ontario Hydro method is listed in Table 9. The total mercury concentration in the flue gas (present as total mercury concentration at the AHPC inlet) ranged from 10.6 to $13.2 \mu \mathrm{g} / \mathrm{Nm}^{3}$, which is slightly lower than the theoretical value of $15.1 \mu \mathrm{g} / \mathrm{Nm}^{3}$ obtained from the coal combustion calculation based on the coal analysis. A possible reason is the underestimated inlet dust loading. However, considering the complexity of mercury analysis, the measured mercury results are close to the theoretical value.

The Day 1 baseline mercury species distributions are plotted as a function of sampling location in Figure 8. At the AHPC inlet, the mercury associated with particulate was $5.91-7.12 \mu \mathrm{g} / \mathrm{Nm}^{3}$ and the oxidized mercury was $5.2-6.55 \mu \mathrm{g} / \mathrm{Nm}^{3}$, while the elemental mercury vapor was at a surprisingly low level of $0.87 \mu \mathrm{g} / \mathrm{Nm}^{3}$. The normalized mercury species distributions, shown in Figure 9, indicate that around 50\% of total mercury was associated with the particulate phase, another $43 \%$ of total mercury was in the oxidized state, and only about $7 \%$ was in the elemental state. The mercury concentrations at the AHPC outlet are also shown in Figure 8 . All the mercury associated with the fly ash particles was completely removed from the flue gas because of the extremely high particle collection efficiency $(>99.99 \%$ based on dust loading measured at the AHPC inlet and outlet). However, gas-phase mercury including elemental and oxidized penetrated the AHPC with virtually no capture, resulting in an elemental mercury concentration of $1-1.23 \mu \mathrm{g} / \mathrm{Nm}^{3}$ and an oxidized mercury concentration of 4.72-6.46 $\mu \mathrm{g} / \mathrm{Nm}^{3}$ at the outlet, almost the same level as that of the inlet. The normalized mercury distributions at the outlet are also plotted in Figure 9. The collection efficiencies of mercury species by the AHPC system itself are shown in Figure 10. A 100\% collection efficiency of mercury associated with fly ash was achieved because of the excellent capture efficiency of particulate by the AHPC unit. For the mercury vapor, results indicate $4.8 \%$ of oxidized mercury vapor was removed by the system, 
Table 9. Summary of Ontario Hydro Mercury Results, dry flue gas at 3.0\% $\mathrm{O}_{2}\left(\mu \mathrm{g} / \mathrm{Nm}^{3}\right)$

\begin{tabular}{|c|c|c|c|c|c|}
\hline & & $\mathrm{Hg}^{0}$ & $\mathrm{Hg}^{+}$ & Hg (Particulate) & $\mathrm{Hg}$ (Total) \\
\hline \multirow{4}{*}{ Day 1} & \multirow{2}{*}{ Inlet } & 0.87 & 5.2 & 7.12 & 13.19 \\
\hline & & 0.87 & 6.55 & 5.91 & 13.33 \\
\hline & \multirow{2}{*}{ Outlet } & 1.0 & 4.72 & 0 & 5.72 \\
\hline & & 1.23 & 6.46 & 0 & 7.69 \\
\hline \multirow{4}{*}{ Day 2} & Inlet & 1.04 & 3.04 & 6.49 & 10.57 \\
\hline & \multirow{3}{*}{ Outlet } & 0.75 & 0 & 0 & 0.75 \\
\hline & & 0.87 & 0.55 & 0 & 1.42 \\
\hline & & 0.74 & 0.06 & 0 & 0.80 \\
\hline \multirow{4}{*}{ Day 3} & Inlet & 1.13 & 5.99 & 4.32 & 11.44 \\
\hline & \multirow{3}{*}{ Outlet } & 0.11 & 0.27 & 0 & 0.38 \\
\hline & & 0.14 & 0.46 & 0 & 0.6 \\
\hline & & 0.14 & 0.05 & 0 & 0.19 \\
\hline \multirow{4}{*}{ Day 4} & Inlet & 0.41 & 2.64 & 10.2 & 13.25 \\
\hline & \multirow{3}{*}{ Outlet } & 0.21 & 1.07 & 0 & 1.28 \\
\hline & & 0.13 & 0.75 & 0 & 0.88 \\
\hline & & 0.13 & 0.96 & 0 & 1.09 \\
\hline \multirow[t]{2}{*}{ Day 5} & Inlet & 0.62 & 5.5 & 5.86 & 11.98 \\
\hline & Outlet & 0.13 & 0.61 & 0 & 0.74 \\
\hline \multirow[t]{2}{*}{ Day 5} & Inlet & 0.42 & 3.88 & 7.83 & 12.13 \\
\hline & Outlet & 0.09 & 0.54 & 0 & 0.63 \\
\hline
\end{tabular}

Day 1 - No carbon injection, AHPC, $3.0 \mathrm{~m} / \mathrm{min}(10 \mathrm{ft} / \mathrm{min})$.

Day 2 - Carbon: $0.65 \mathrm{lb} / \mathrm{hr}$, AHPC $3.0 \mathrm{~m} / \mathrm{min}(10 \mathrm{ft} / \mathrm{min})$.

Day 3 - Carbon: $0.33 \mathrm{lb} / \mathrm{hr}$, pulse jet, $1.5 \mathrm{~m} / \mathrm{min}(5 \mathrm{ft} / \mathrm{min})$.

Day 4 - Carbon: $0.65 \mathrm{lb} / \mathrm{hr}$, AHPC $3.0 \mathrm{~m} / \mathrm{min}(10 \mathrm{ft} / \mathrm{min})$.

Day 5 - Carbon: $0.33 \mathrm{lb} / \mathrm{hr}$, AHPC $1.5 \mathrm{~m} / \mathrm{min}(5 \mathrm{ft} / \mathrm{min})$.

Day 5 - Carbon: $0.33 \mathrm{lb} / \mathrm{hr}$, Pulse jet $1.5 \mathrm{~m} / \mathrm{min}(5 \mathrm{ft} / \mathrm{min})$.

And a $! 28.2 \%$ collection efficiency of elemental mercury vapor was observed. However, considering the low inlet $\mathrm{Hg}^{0}$ and the blank correction, the outlet $\mathrm{Hg}^{0}$ and $\mathrm{Hg}^{+}$concentrations were similar to the inlet values, and the $49.4 \%$ overall collection efficiency of mercury by the AHPC without carbon injection was the result of capturing particulate-bound mercury.

On the Day 2 sampling test, the unit was operated in an AHPC mode $(70 \mathrm{~mA}, 58 \mathrm{kV}$, $3.0 \mathrm{~m} / \mathrm{min}$ [10 ft/min], 20-min bag-cleaning interval [BCI]), with a carbon injection of $0.29 \mathrm{~kg} / \mathrm{hr}$ $(0.65 \mathrm{lb} / \mathrm{hr})$ (corresponding to $24 \mathrm{~kg}$ of carbon/million $\mathrm{m}^{3}$ [1.5 lb carbon/million acf]). Results from one inlet and three outlet Ontario Hydro samples are shown in Figure 11. In the presence of the activated carbon in the flue gas, the outlet mercury emission was reduced to $0 \mu \mathrm{g} / \mathrm{Nm}^{3}$ of particulate mercury, $0-0.55 \mu \mathrm{g} / \mathrm{Nm}^{3}$ of oxidized mercury, and $0.74-0.85 \mu \mathrm{g} / \mathrm{Nm}^{3}$ of elemental mercury vapor. The corresponding collection efficiencies are plotted in Figure 12. Again, the 


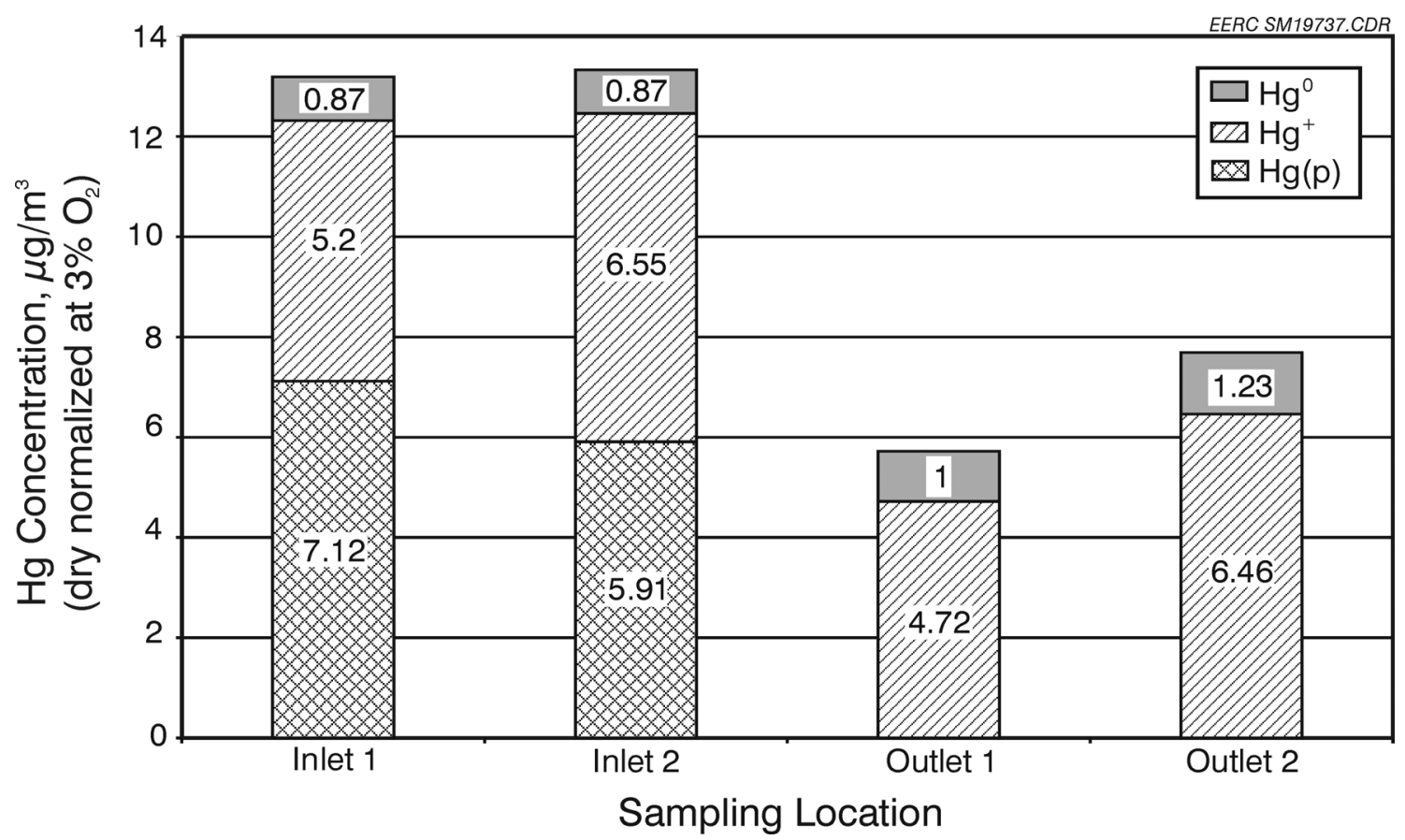

Figure 8. Day 1 - mercury species concentration in flue gas across the AHPC (10 ft/min, 20-minute BCI, multibank cleaning, no carbon injection).

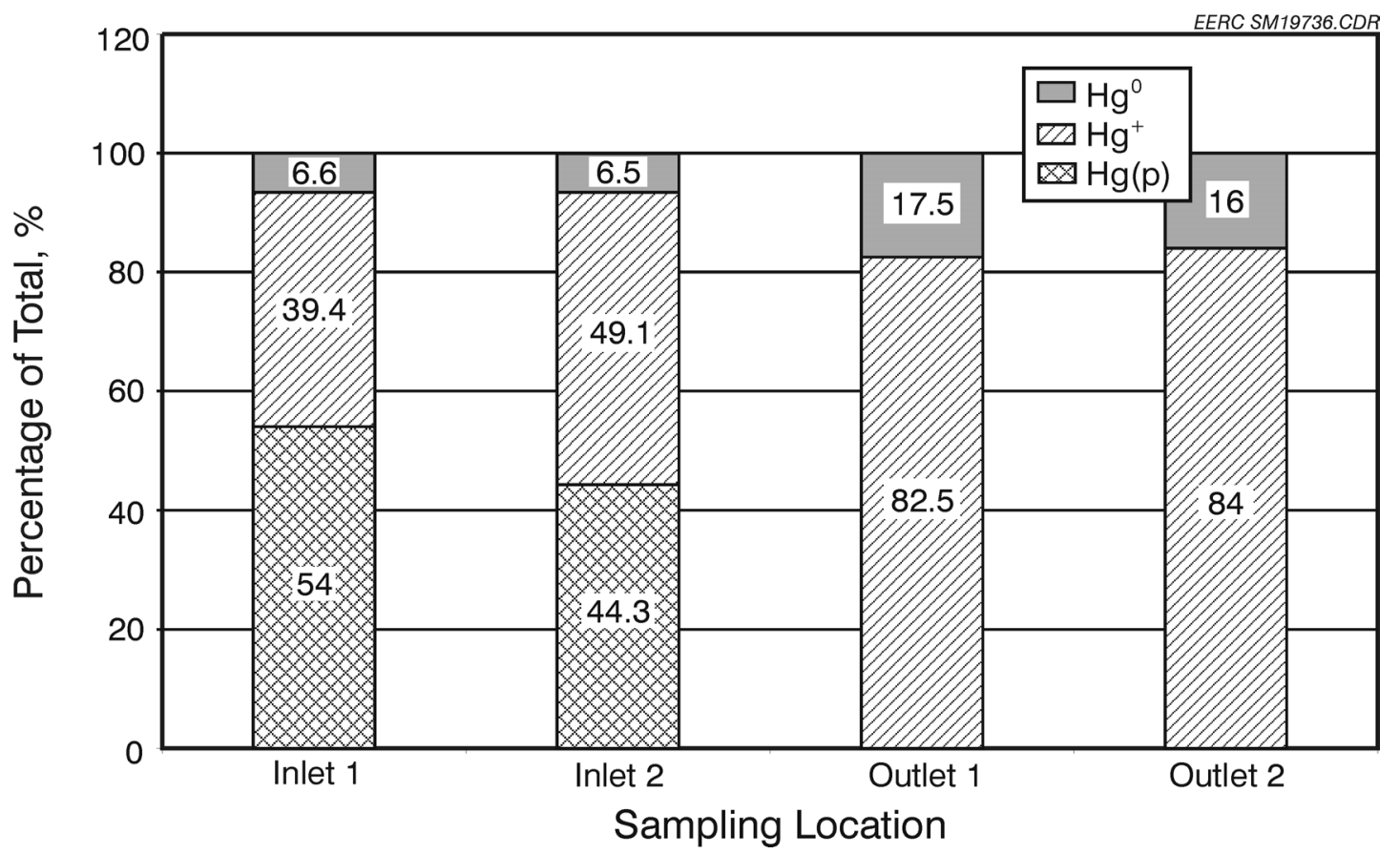

Figure 9. Day 1 - percentage of mercury species distribution in flue gas across the AHPC (10 ft/min, 20-minute BCI, multibank cleaning, no carbon injection). 


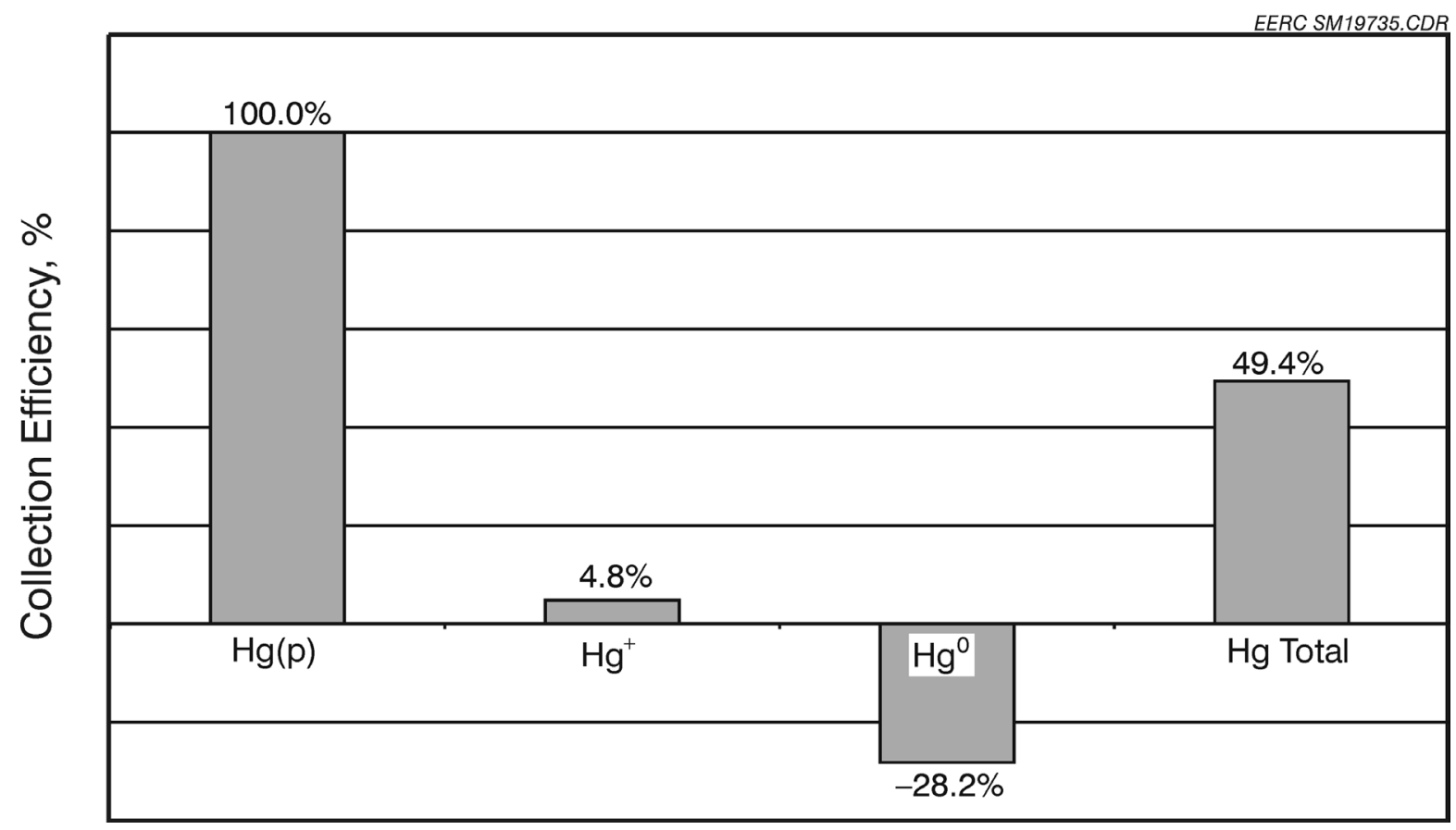

Figure 10. Day 1 - mercury species collection efficiency in AHPC mode (10 ft/min, 20-minute BCI, multibank cleaning, no carbon injection).

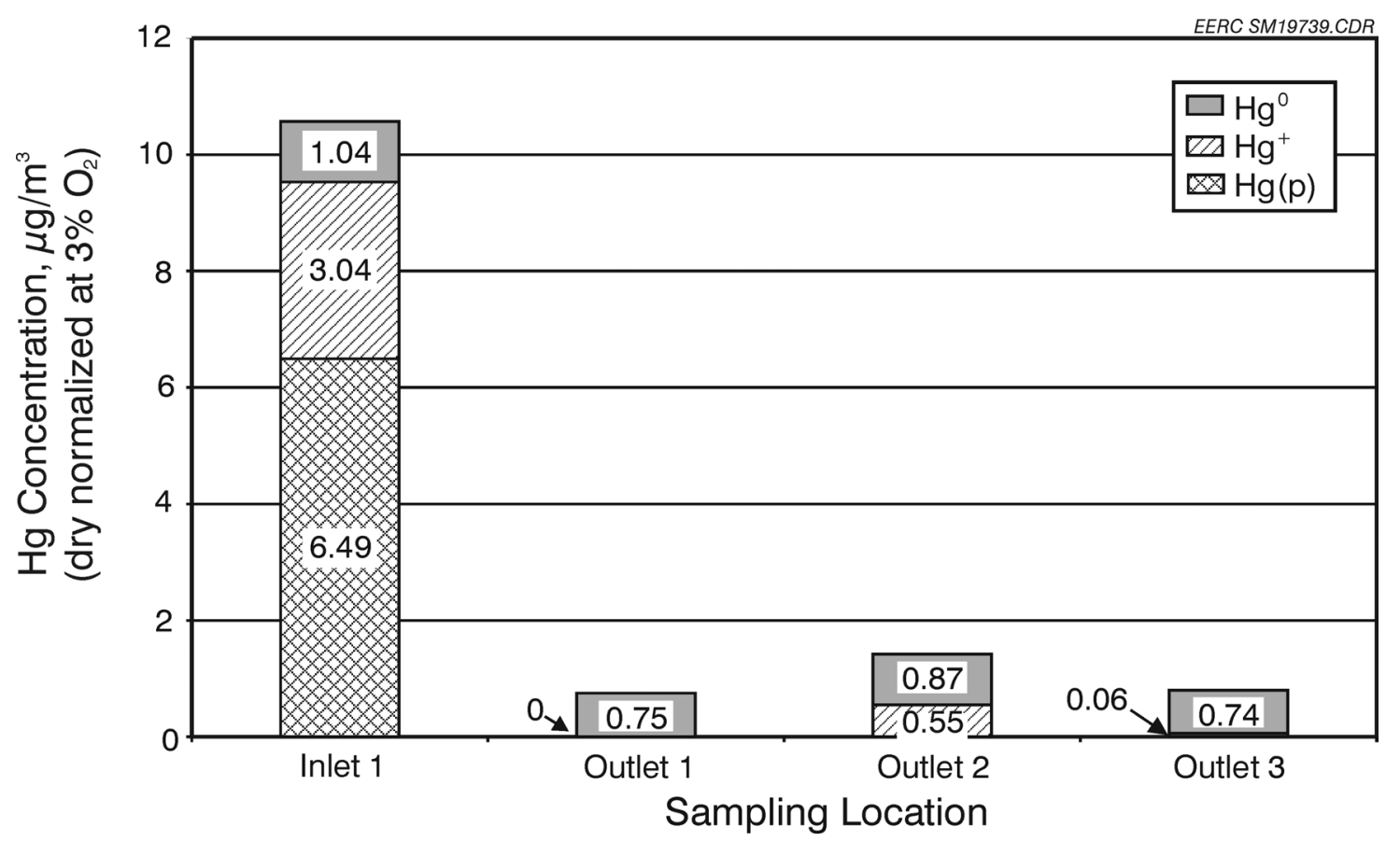

Figure 11. Day 2 - mercury species concentration in flue gas across the AHPC unit in AHPC mode (10 ft/min, 20-minute BCI, multibank cleaning, carbon: $0.65 \mathrm{lb} / \mathrm{hr})$. 


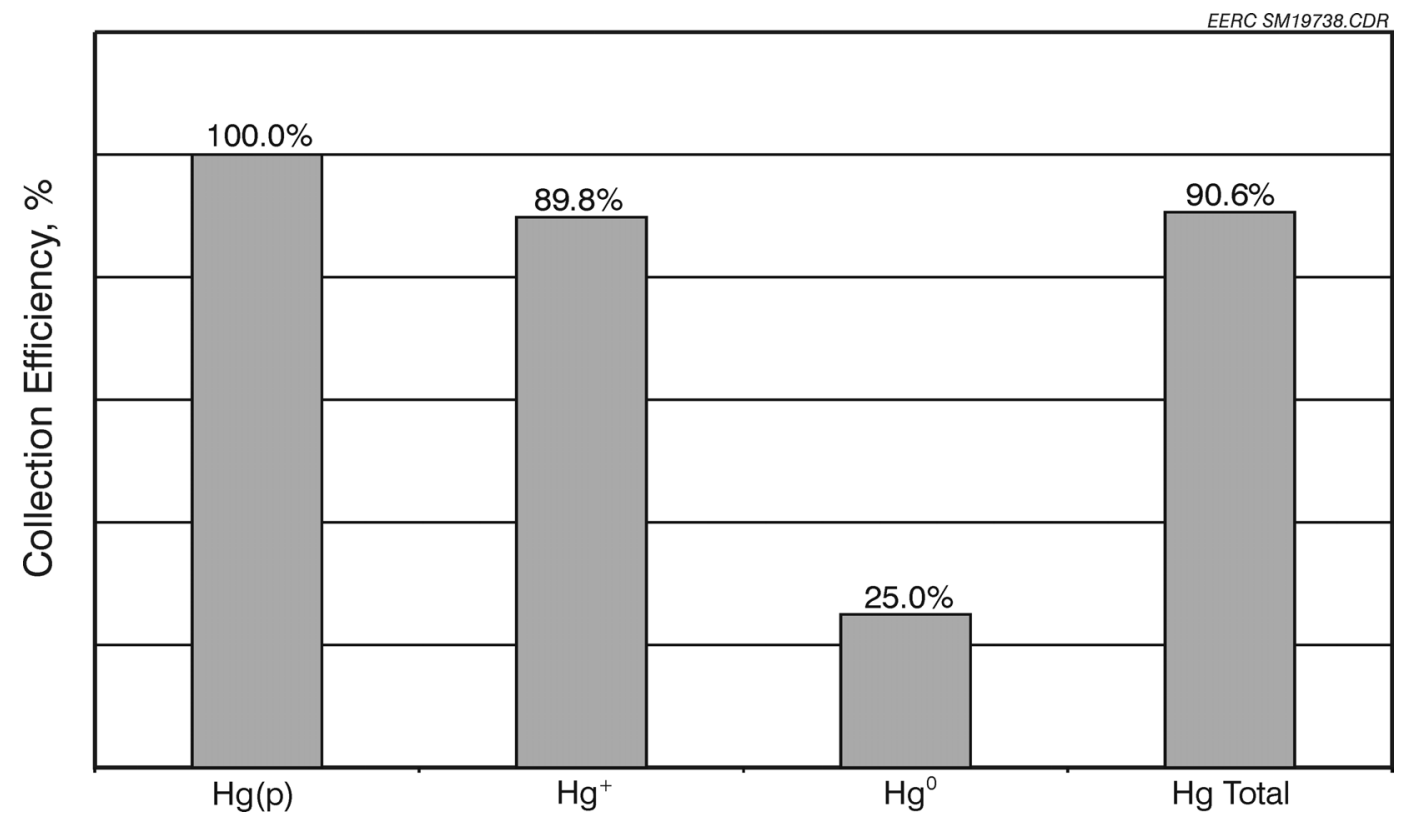

Figure 12. Day 2 - mercury species collection efficiency in AHPC mode (10 ft/min, 20-minute BCI, multibank cleaning, carbon: $0.65 \mathrm{lb} / \mathrm{hr}$ ).

removal efficiency for particulate-associated mercury was $100 \%$. The oxidized mercury collection efficiency was dramatically increased from $4.8 \%$ under no carbon injection to $89.8 \%$ under the carbon injection rate of $24 \mathrm{~kg}$ of carbon/million $\mathrm{m}^{3}$ (1.5 lb carbon/million acf), showing the DARCO FGD activated carbon efficiently adsorbed the oxidized mercury on the sorbent surface. The indicated elemental mercury vapor collection efficiency was $25 \%$, but because of the low inlet $\mathrm{Hg}^{0}$ and blank correction, there is more uncertainty as to the exact removed percentage of $\mathrm{Hg}^{0}$. The overall mercury collection of $90.6 \%$ compared to $49 \%$ without carbon indicates the carbon injection was effective.

On Day 3, the AHPC unit was then operated in pulse-jet mode (without high-voltage power) with a 20-min BCI. In order to keep the pressure drop across the system at a reasonable level, the $\mathrm{A} / \mathrm{C}$ ratio was reduced to $1.5 \mathrm{~m} / \mathrm{min}(5 \mathrm{ft} / \mathrm{min})$ and the carbon injection rate was correspondingly reduced to $0.15 \mathrm{~kg} / \mathrm{hr}(0.33 \mathrm{lb} / \mathrm{hr})$ to keep the same carbon-to-flue gas ratio of 24 $\mathrm{kg}$ of carbon/million $\mathrm{m}^{3}(1.5 \mathrm{lb}$ carbon/million acf). The measured mercury species concentrations (one inlet and three outlet samples) are plotted in Figure 13. The inlet mercury species distribution was similar to the previous two days. The outlet mercury was at a very low level in the presence of carbon injection: $0 \mu \mathrm{g} / \mathrm{Nm}^{3}$ of particle associated mercury, $0.07-0.46 \mu \mathrm{g} / \mathrm{Nm}^{3}$ of oxidized mercury, and $0.11-0.14 \mu \mathrm{g} / \mathrm{Nm}^{3}$ of elemental mercury vapor. The corresponding mercury collection efficiencies are plotted in Figure 14, showing removal efficiencies of oxidized mercury and elemental mercury of $95.6 \%$ and $88.5 \%$, respectively, and an overall mercury capture efficiency up to $96.6 \%$, which is somewhat better than the $90.6 \%$ achieved in the Day 2 sampling test. For Day 3, the outlet values should be more accurate because no blank correction was needed. Longer residence time at the reduced $\mathrm{A} / \mathrm{C}$ ratio of $1.5 \mathrm{~m} / \mathrm{min}(5 \mathrm{ft} / \mathrm{min})$ and a lower temperature may have contributed to the somewhat lower mercury emissions compared to Day 2. 


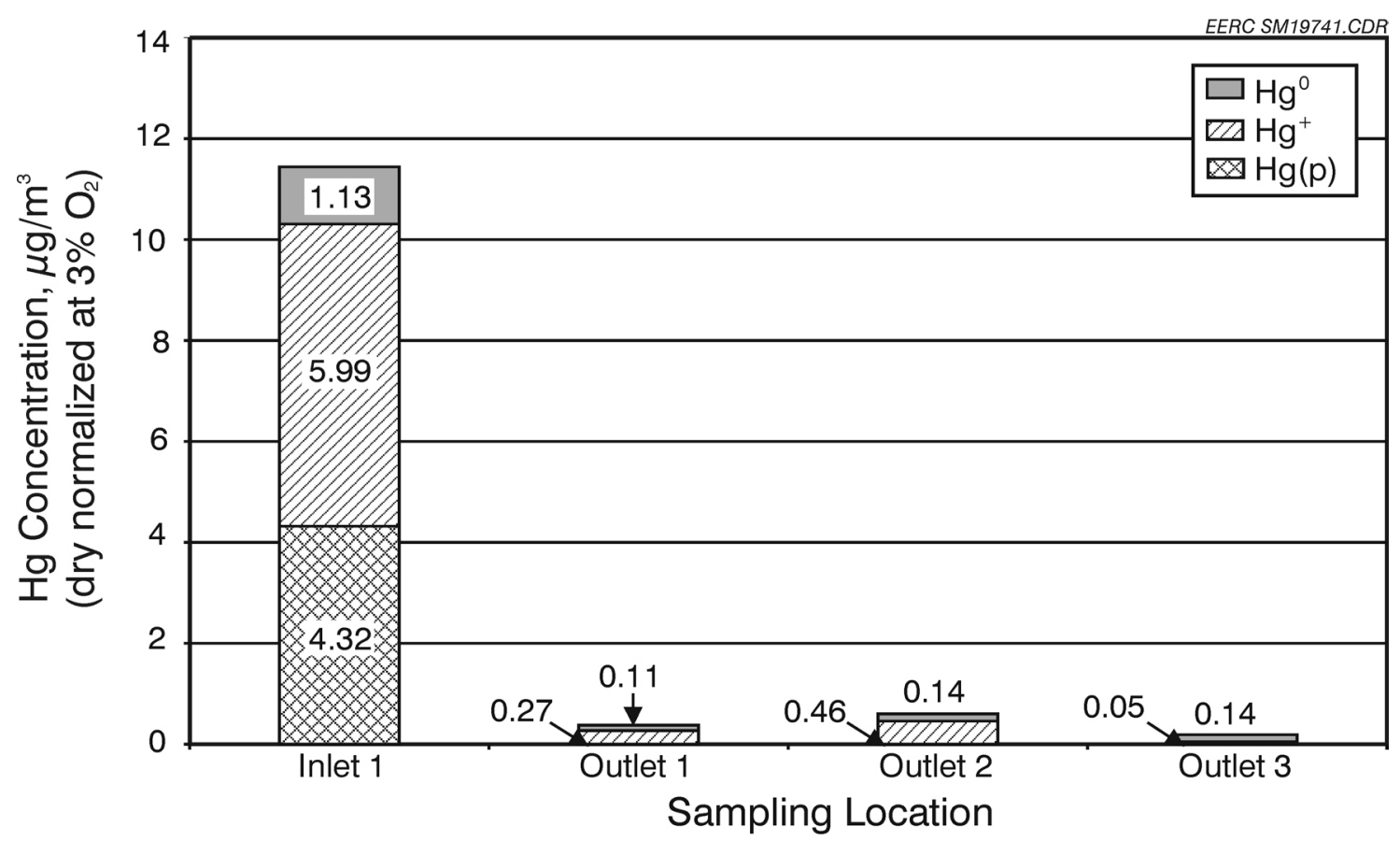

Figure 13. Day 3 - mercury species concentration in flue gas across the AHPC unit in pulse-jet mode $(5 \mathrm{ft} / \mathrm{min}, 20$-minute $\mathrm{BCI}$, multibank cleaning, carbon: $0.33 \mathrm{lb} / \mathrm{hr})$.

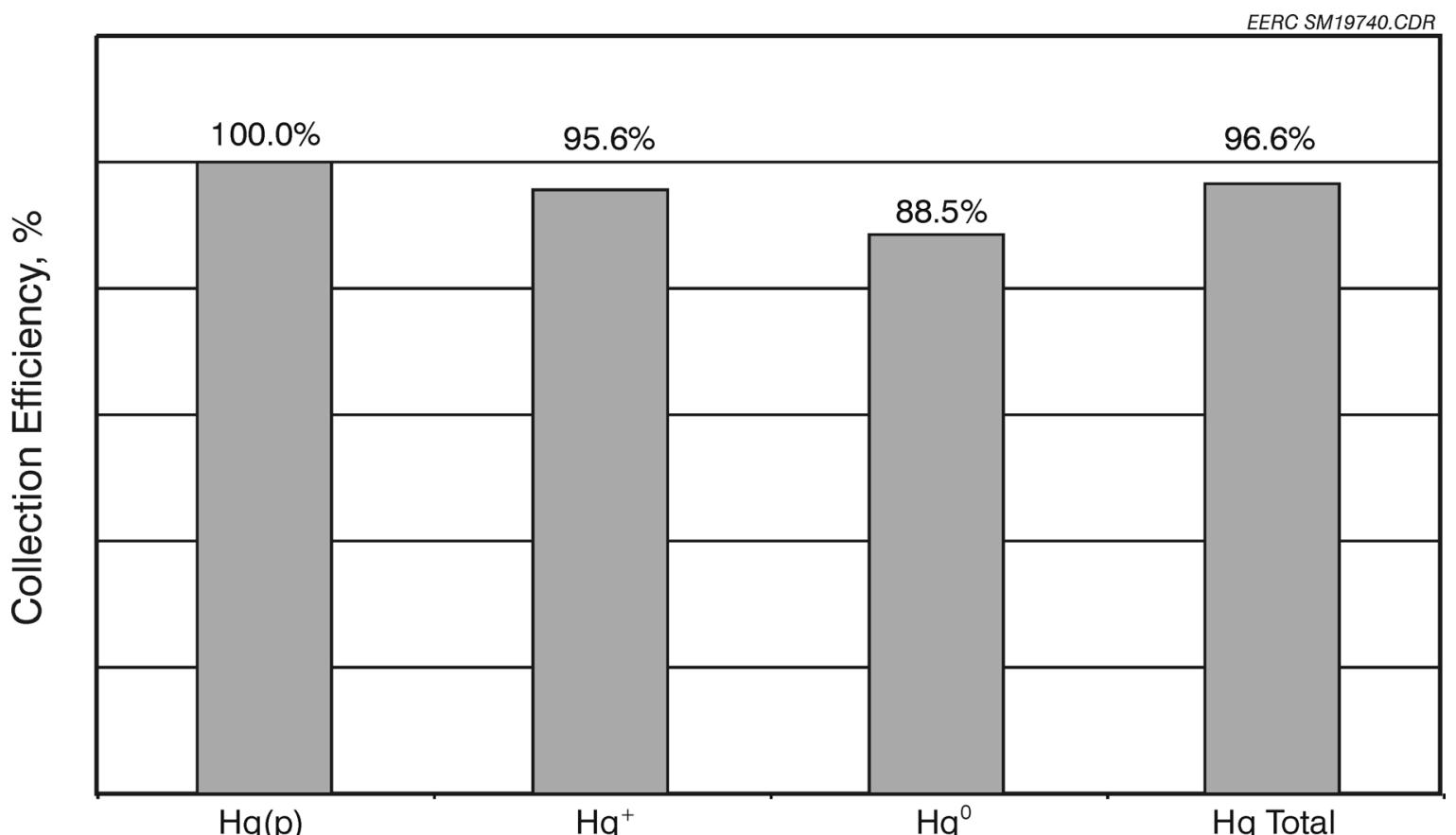

Figure 14. Day 3 - mercury species collection efficiency in pulse-jet mode (5 ft/min, 20-minute BCI, multibank cleaning, carbon: $0.33 \mathrm{lb} / \mathrm{hr}$ ). 
The Day 4 sampling test was a repeat of the Day 2 test (AHPC mode, 20-min BCI, $3.0 \mathrm{~m} / \mathrm{min}[10 \mathrm{ft} / \mathrm{min}]$ of A/C ratio, and $0.29 \mathrm{~kg} / \mathrm{hr}[0.65 \mathrm{lb} / \mathrm{hr}]$ carbon injection rate). The mercury concentrations and collection efficiencies (shown in Figures 15 and 16) are in good agreement with the results obtained in the Day 2 test. The total mercury collection efficiency was $91.8 \%$, almost the same as the $90.6 \%$ achieved in the Day 2 test, and the removal efficiency for oxidized mercury and elemental mercury was $64.0 \%$ and $61.8 \%$, respectively.

For Day 5, the unit was operated with carbon injection in both AHPC and pulse-jet modes at the same $\mathrm{A} / \mathrm{C}$ ratio of $1.5 \mathrm{~m} / \mathrm{min}(5 \mathrm{ft} / \mathrm{min})$. The tests provided a better comparison between the two operating modes because the residence time and temperature were constant. The measured mercury concentrations under the two operating modes are plotted in Figure 17. The total inlet mercury concentration was $11.98 \mu \mathrm{g} / \mathrm{Nm}^{3}$ in AHPC mode and $12.13 \mu \mathrm{g} / \mathrm{Nm}^{3}$ in pulse-jet mode, indicating constant inlet conditions. The outlet mercury was also similar for both operating modes. The collection efficiencies are plotted in Figure 18, showing the removal efficiencies for oxidized, elemental, and total mercury were the same for both modes. However, the system was only operated for 2 hours for each test, and more long-term experiments are necessary to verify these results.

During the week, the sorbent was injected only during the day, and after completing the mercury sampling, the carbon injection was shut off overnight to allow the unit to return to baseline conditions. Four hopper ash samples were collected each day as a function of time except for the first day and the fifth day when two samples and three samples were collected, respectively. The first sample usually was regarded as baseline ash, and the rest represented ash samples from the carbon injection tests. The hopper ash samplers were then acid-digested and measured for mercury concentration. The results are presented in Table 10. For comparison, the filter ash mercury from the inlet Ontario Hydro samples is also reported in Table 10. For the Day 1 baseline test, both the inlet filter ash and hopper ash had almost the same mercury concentration at approximately the same operating time. With carbon injection, the mercury concentration in the hopper ash gradually increased, showing the mercury vapor was absorbed on the activated carbon and was removed from the flue gas by the filter bags. A fly ash sample collected in the thimble filter used in CEM sampling at the inlet location was also analyzed for mercury concentration and is shown in Table 10 . The mercury concentration of $8.22 \mu \mathrm{g} / \mathrm{Nm}^{3}$ on the CEM filter fly ash was much higher than that of the hopper ash. One possible reason could be that the sampling nozzle was pointing downstream so the fine fly ash collected in the filter by nonisokinetic sampling had a greater enrichment of mercury compared to that of larger size fly ash particles. Another factor could be that this filter was continually used over a whole day so the extended exposure time may lead to higher mercury adsorption.

The mercury concentrations for the AHPC hopper ash samples along with percent loss on ignition (LOI) shown in Table 10 indicate a general trend of increasing values with the carbon injection, as would be expected. However, because of the varying baseline values, it is not possible to complete a good mass balance. For the measured inlet dust loading, the expected increase in carbon in the fly ash (for the given carbon injection rate) is about $1.6 \%$. The LOI data from Days 4 and 5 are in reasonable agreement with this level of increase. The varying baseline LOI levels and the short-term tests do not allow for a better mass balance closure. The morning 


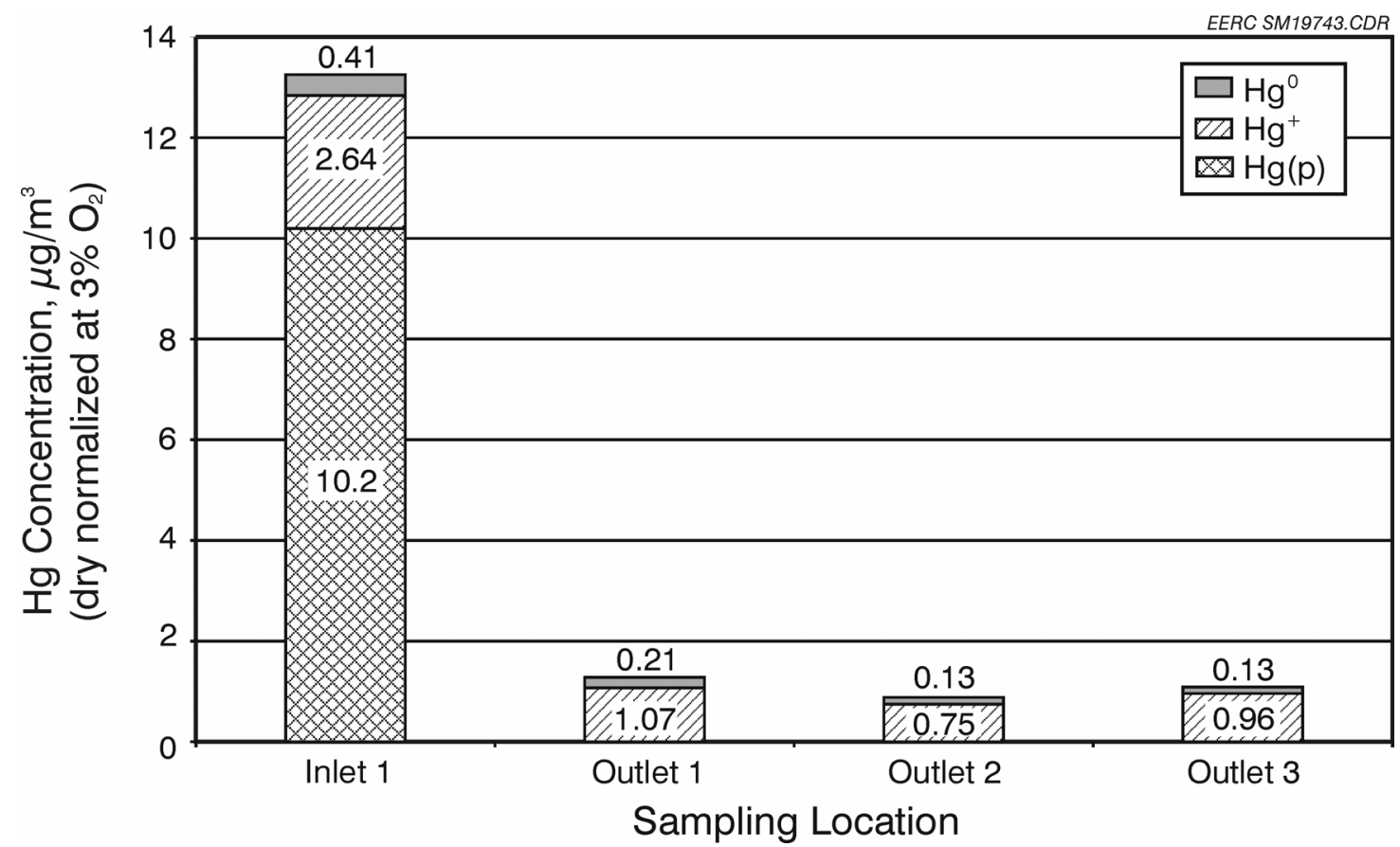

Figure 15. Day 4 - mercury species concentration in flue gas across the AHPC unit in AHPC mode (10 ft/min, 20-minute BCI, multibank cleaning, carbon: $0.65 \mathrm{lb} / \mathrm{hr}$ ).

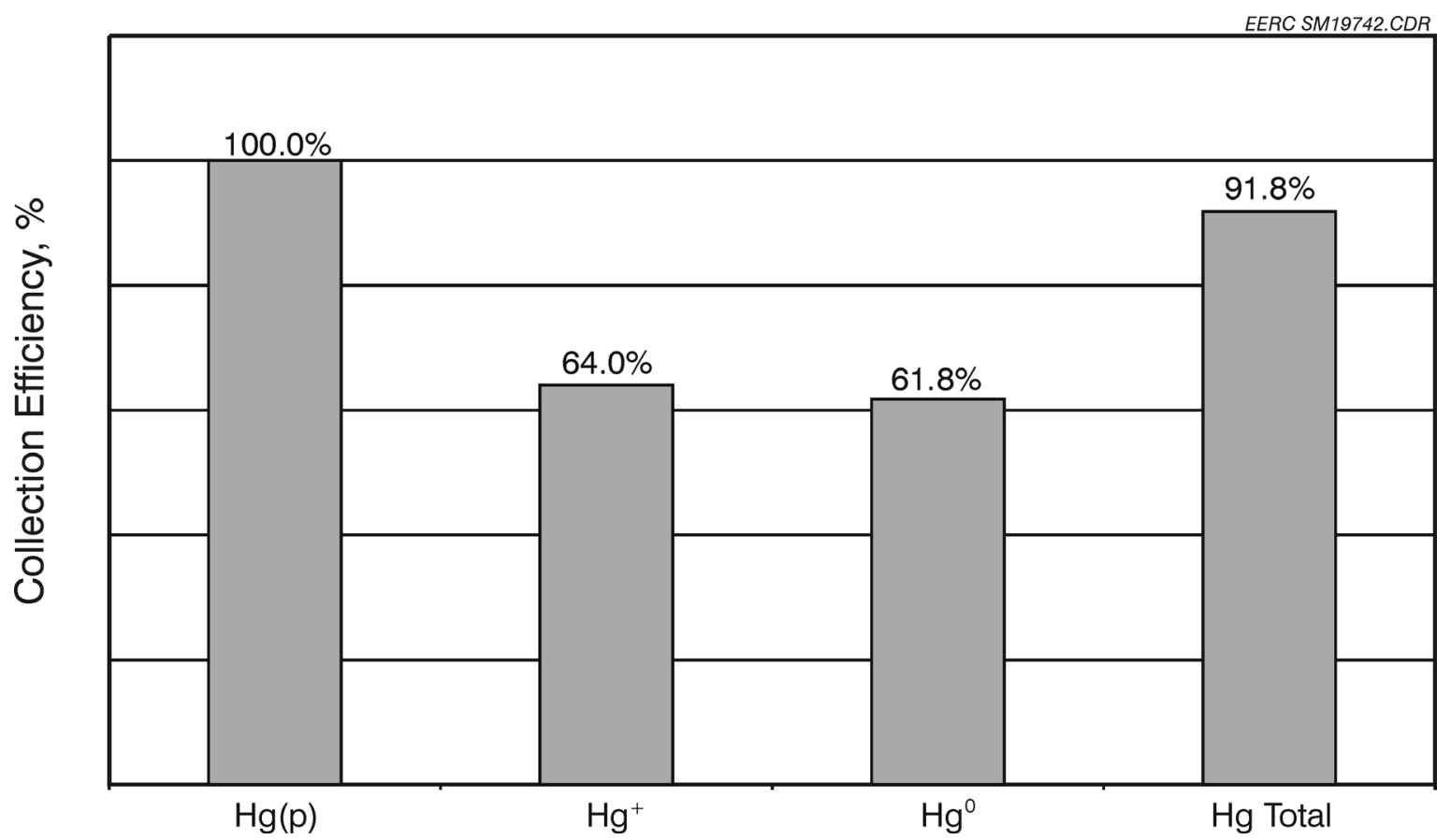

Figure 16. Day 4 - mercury species collection efficiency in AHPC mode (10 ft/min, 20-minute BCI, multibank cleaning, carbon: $0.65 \mathrm{lb} / \mathrm{hr}$ ). 


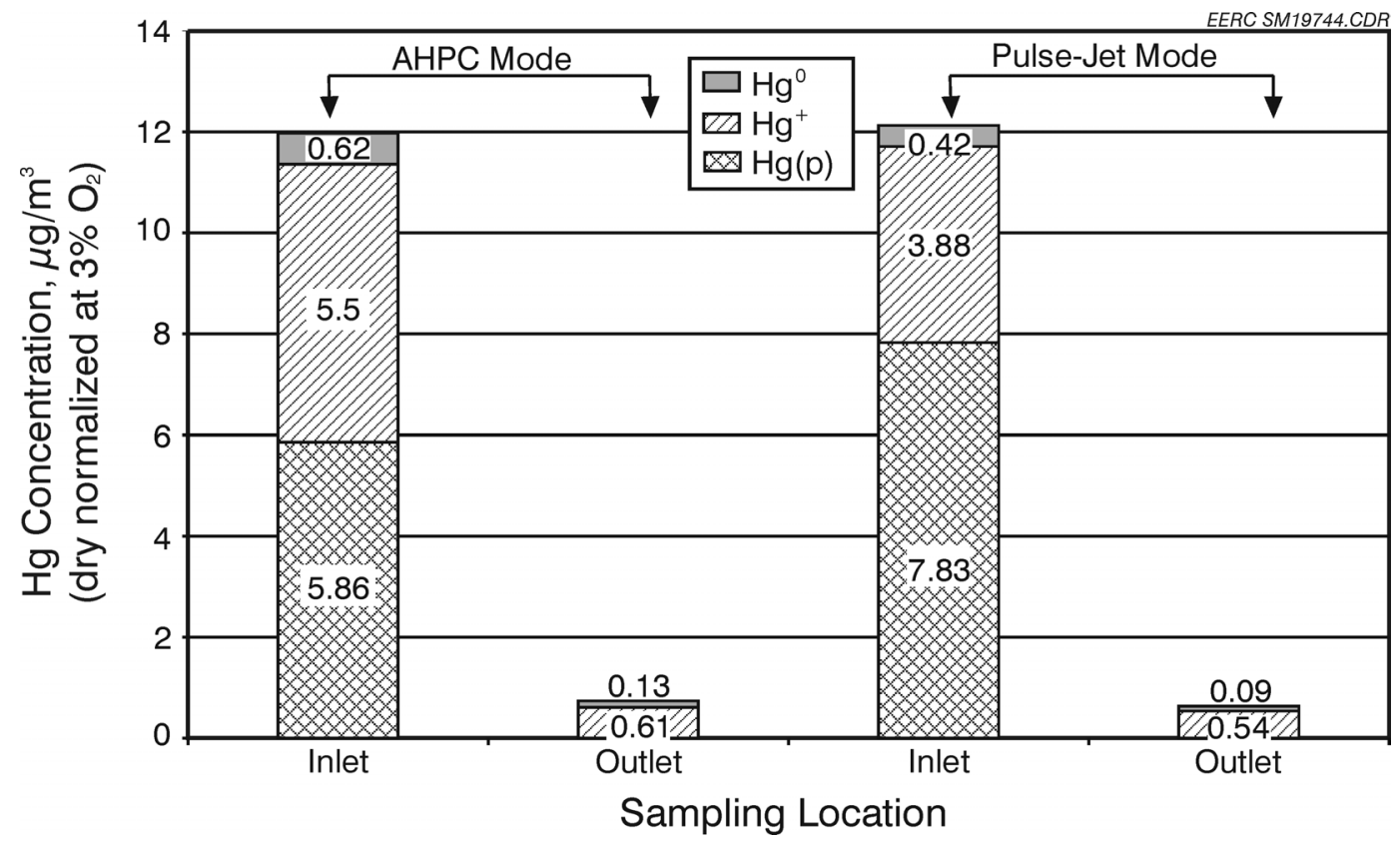

Figure 17. Day 5 - mercury species concentration in flue gas across the AHPC unit at Big Stone in both AHPC and pulse-jet mode.

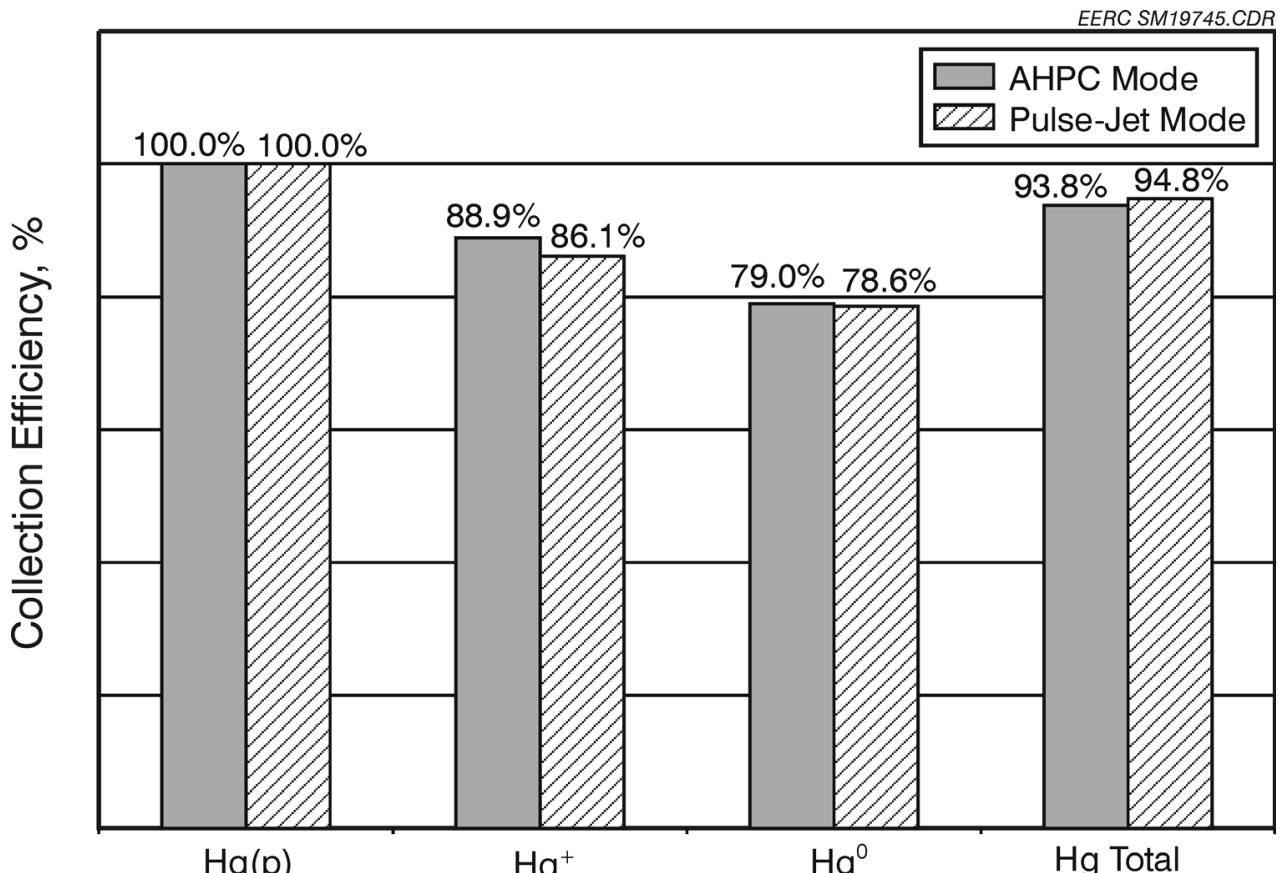

Figure 18. Day 5 - mercury species collection efficiency under AHPC and pulse-jet mode. 
Table 10. Mercury Concentration in Fly Ash

\begin{tabular}{|c|c|c|c|c|}
\hline Test Day & Sample Type & Time Sample Taken & Hg Concentration, $\mu \mathrm{g} / \mathrm{g}$ & $\%$ LOI \\
\hline Day 1 & Hopper Ash Baseline & $11: 01$ & 1.84 & \\
\hline Day 1 & Hopper Ash Baseline & 14:00 & 1.53 & 0.48 \\
\hline Day 1 & Inlet Filter & $9: 20-11: 20$ & 1.98 & \\
\hline Day 1 & Inlet Filter & 12:05-14:05 & 1.58 & \\
\hline Day 2 & Hopper Ash Baseline & $7: 10$ & 1.34 & 0.79 \\
\hline Day 2 & Carbon Injection AHPC & 10:02 & 2.58 & \\
\hline Day 2 & Carbon Injection AHPC & 12:01 & 2.74 & \\
\hline Day 2 & Carbon Injection AHPC & $14: 00$ & 3.06 & 1.56 \\
\hline Day 2 & Inlet Filter & $8: 00-10: 00$ & 1.67 & \\
\hline Day 3 & Hopper Ash Baseline & $7: 18$ & 1.67 & 1.86 \\
\hline Day 3 & Carbon Injection Pulse Jet & $11: 00$ & 3.58 & \\
\hline Day 3 & Carbon Injection Pulse Jet & 14:04 & 3.94 & \\
\hline Day 3 & Carbon Injection Pulse Jet & $16: 01$ & 3.62 & 2.15 \\
\hline Day 3 & Inlet Filter & $10: 23-12: 23$ & 1.59 & \\
\hline Day 4 & Hopper Ash Baseline & $7: 20$ & 1.64 & 0.71 \\
\hline Day 4 & Carbon Injection AHPC & 11:01 & 2.71 & \\
\hline Day 4 & Carbon Injection AHPC & 13:04 & 2.80 & \\
\hline Day 4 & Carbon Injection AHPC & 16:01 & 3.36 & 1.90 \\
\hline Day 4 & Inlet Filter & 9:00-11:00 & 2.89 & \\
\hline Day 5 & Hopper Ash Baseline & $7: 18$ & 3.09 & 1.67 \\
\hline Day 5 & Carbon Injection AHPC & 10:01 & 3.46 & \\
\hline Day 5 & Carbon Injection Pulse Jet & $13: 01$ & 3.90 & 2.45 \\
\hline Day 5 & Inlet Filter & $8: 00-10: 00$ & 2.18 & \\
\hline Day 5 & Inlet Filter & 11:00-13:00 & 2.89 & \\
\hline Day 4 & Inlet Filter from CEM & $8: 00-19: 00$ & 8.22 & \\
\hline
\end{tabular}

baseline ash samples were collected after a time without carbon injection, but no attempt was made to clean the AHPC hopper of residual ash between tests so some mixing of the hopper ash from different tests could have occurred. 


\subsection{Mercury CEM Results}

The total mercury vapor concentration and elemental mercury vapor concentration at the AHPC inlet and outlet were continuously monitored on Days $3-5$ by a PS Analytical Sir Galahad analyzer. Since only measuring mercury vapor, a nonisokinetically sample of flue gas was pulled through a thimble filter to remove the fly ash. The particle-free flue gas was then passed through a conversion unit (as shown in Figure 19) where the oxidized mercury could be reduced to elemental state, depending on which side of the pretreatment system the flue was passed through. The mercury exiting the conversion unit was introduced into the PS Analytical Sir Galahad (shown in Figure 20) for elemental or total mercury concentration measurement.

The elemental and total mercury concentrations monitored at the AHPC inlet during the Day 3 test are plotted as a function of operating time and shown in Figure 21. The inlet elemental mercury was around $0.39 \mu \mathrm{g} / \mathrm{Nm}^{3}$, only accounting for $8.4 \%$ of the measured total mercury vapor concentration of $4.62 \mu \mathrm{g} / \mathrm{Nm}^{3}$, which agreed with the Ontario Hydro results. In the presence of activated carbon in flue gas, the total mercury concentration at the outlet was about $0.54 \mu \mathrm{g} / \mathrm{Nm}^{3}$ (also shown in Figure 21), and the elemental mercury concentration in flue gas was below the CEM detection limit, which was in reasonable agreement with the results from the Ontario Hydro method. They both showed that most of the inlet mercury vapor in the flue gas was in the oxidized state and excellent mercury capture in the presence of the activated carbon. At 16:00, the carbon injection was shut down while the outlet was continually monitored for mercury. As seen in Figure 21, the total outlet mercury concentration gradually increased and reached the same level as that of the inlet. The observed slow increase of mercury concentration at the outlet was likely caused by the residual activated carbon in the AHPC chamber after the carbon injection system was shut down.

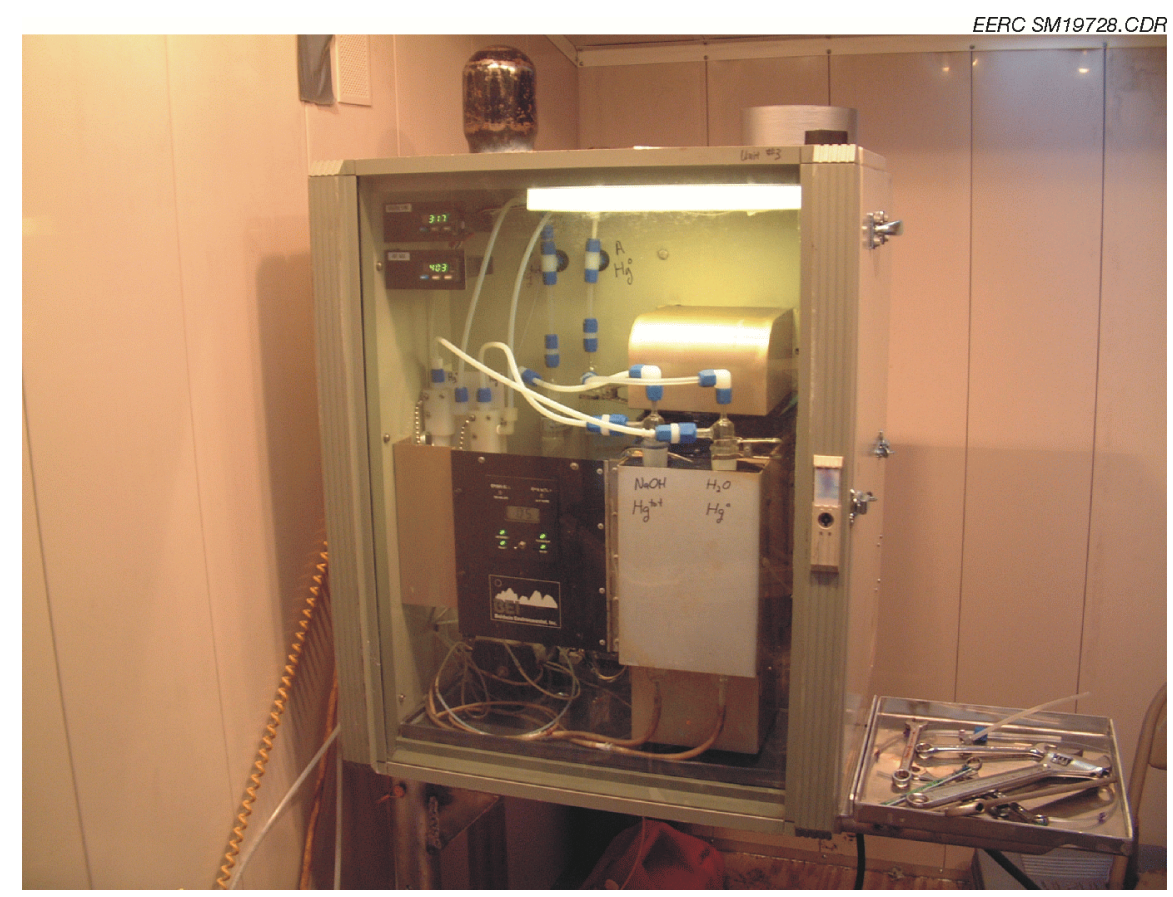

Figure 19. Conversion system CEM mercury sampling. 


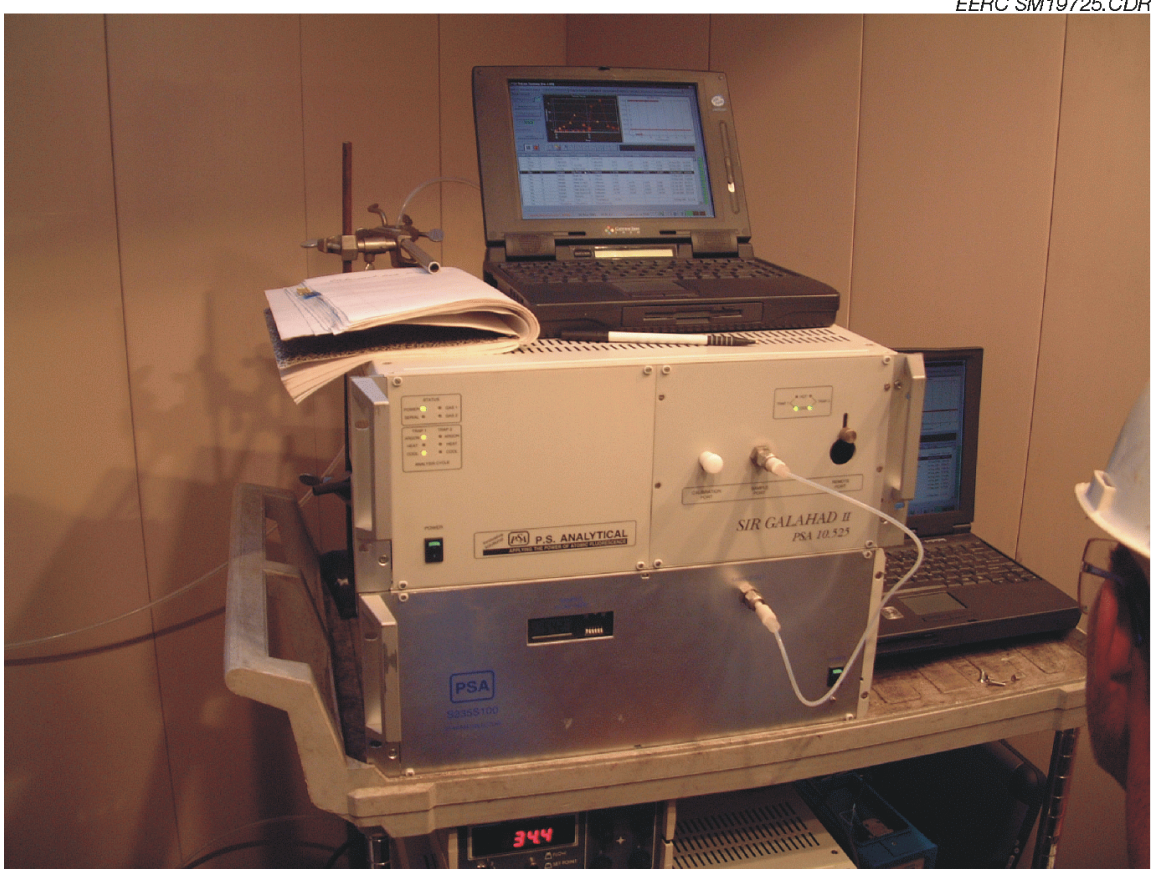

Figure 20. PS Analytical mercury analyzer.

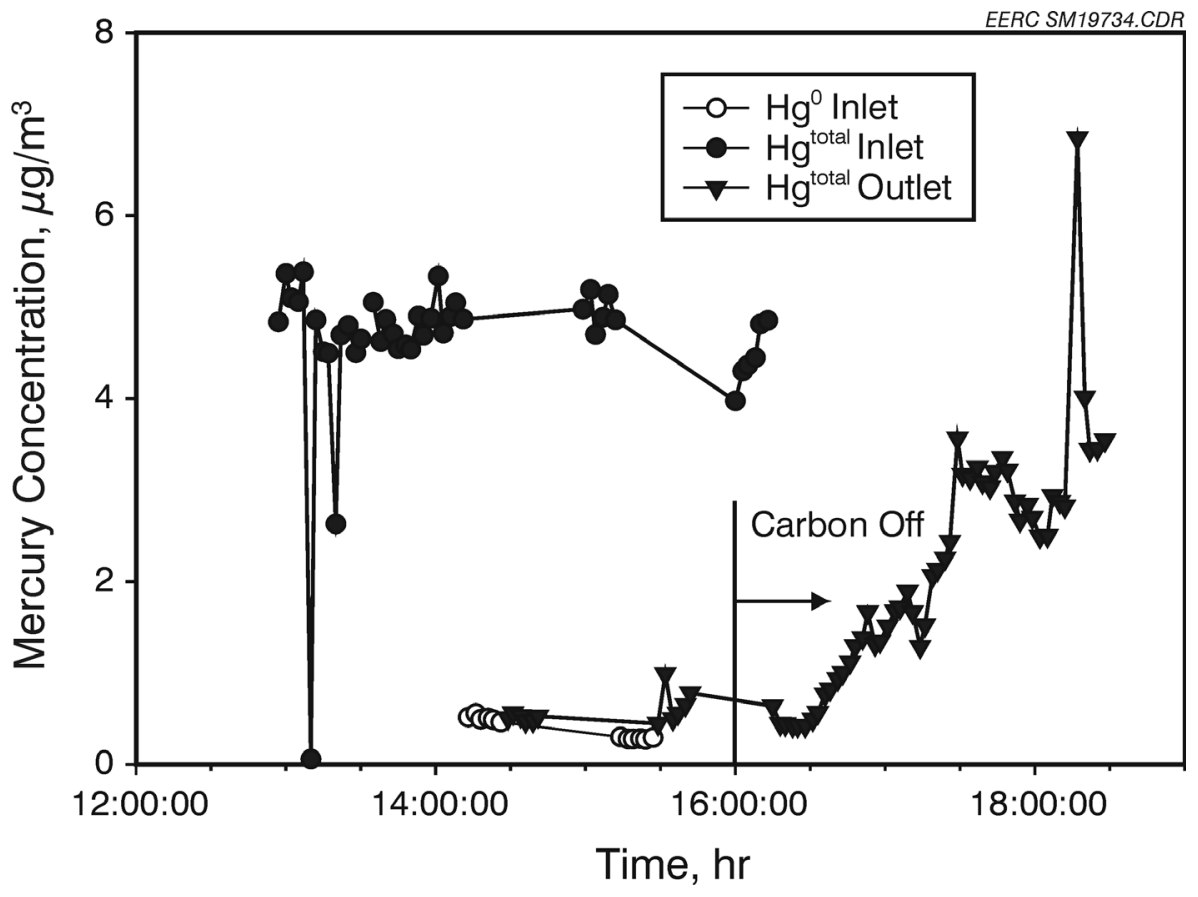

Figure 21. Hg species measurement by CEM - Day 3. 
Figure 22 shows the Day 4 total and elemental mercury concentrations at both the AHPC inlet and outlet when the unit was operated with carbon injection. The total inlet mercury vapor concentration varied from 2.78 to $3.54 \mu \mathrm{g} / \mathrm{Nm}^{3}$, with an average value of $3.09 \mu \mathrm{g} / \mathrm{Nm}^{3}$, which was very close to the $3.05 \mu \mathrm{g} / \mathrm{Nm}^{3}$ from Ontario Hydro analysis. Again, a very low percentage of elemental mercury was observed at the AHPC inlet. The total mercury concentration at the outlet was maintained around $0.6 \mu \mathrm{g} / \mathrm{Nm}^{3}$, showing an efficient mercury vapor removal (including both elemental and oxidized state) due to the activated carbon.

On the Day 5 test, the unit was operated under both AHPC mode and pulse-jet mode to compare the effectiveness of carbon injection on mercury capture at the same $\mathrm{A} / \mathrm{C}$ ratio and temperature. As shown in Figure 23, the total mercury concentration at the inlet was around $2.6 \mu \mathrm{g} / \mathrm{Nm}^{3}$ during the tests, while the total mercury concentration at the outlet was about $0.36 \mu \mathrm{g} / \mathrm{Nm}^{3}$ under both operating modes. The experimental data by the CEM analysis, which were slightly lower than the measured results from Ontario Hydro method, showed both the AHPC and pulse-jet modes have identical collection efficiency of mercury species.

\subsection{AHPC Operational Summary}

During the 5-day sampling test, the AHPC unit was set up at a fixed 20-min BCI with an $\mathrm{A} / \mathrm{C}$ ratio of either $1.5 \mathrm{~m} / \mathrm{min}(5 \mathrm{ft} / \mathrm{min})$ or $3.0 \mathrm{~m} / \mathrm{min}(10 \mathrm{ft} / \mathrm{min})$. The carbon injection rate of $24 \mathrm{~kg} / \mathrm{million} \mathrm{m}^{3}(1.5 \mathrm{lb} /$ million acf $)$ is equivalent to a dust inlet loading of $0.023 \mathrm{~g} /$ actual $\mathrm{m}^{3}$ or $0.034 \mathrm{~g} /$ standard $\mathrm{m}^{3}(0.01 \mathrm{gr} / \mathrm{acf}$ or $0.015 \mathrm{gr} / \mathrm{scf})$. Compared to the average inlet fly ash dust

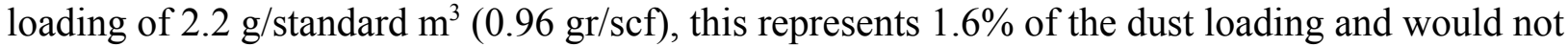
be expected to affect the AHPC pressure drop. From the pressure drop and drag data with and without carbon injection, there was no effect of the carbon injection on AHPC operation.

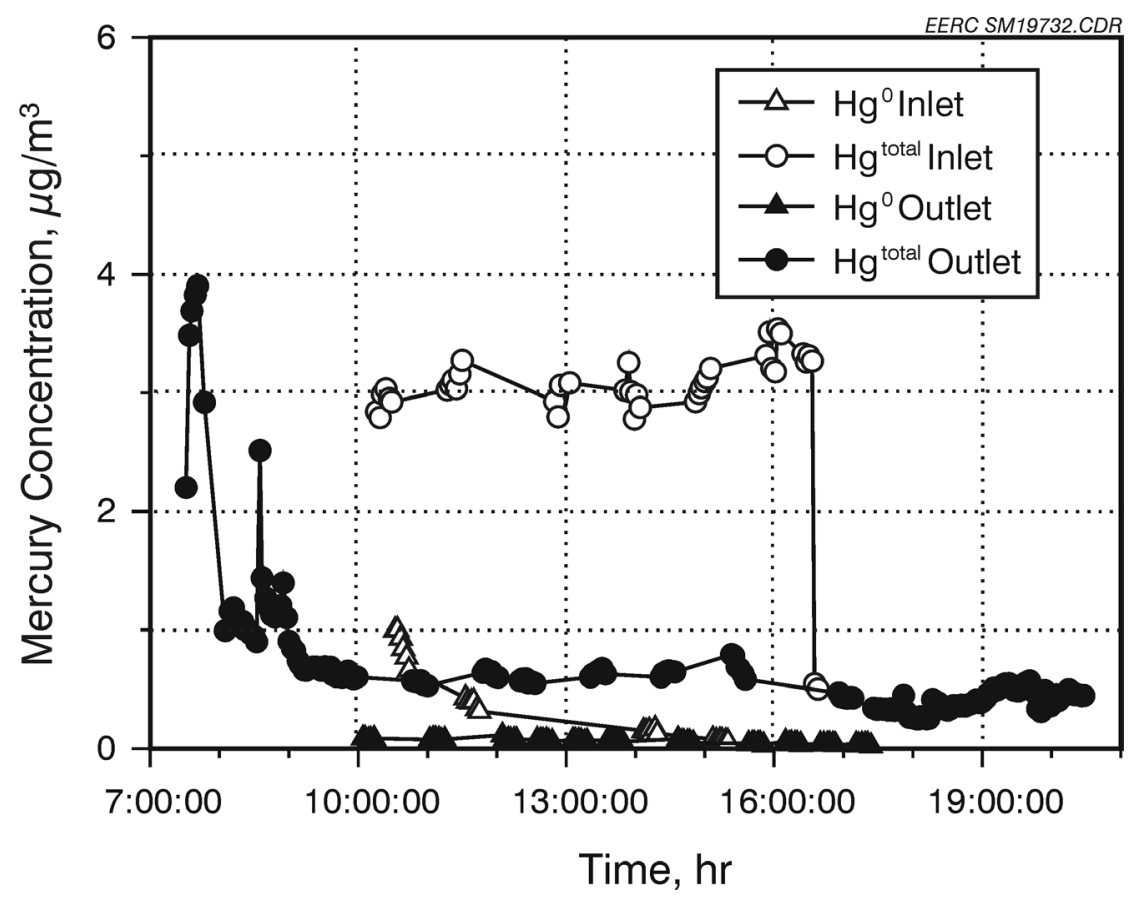

Figure 22. Hg species measurement by CEM - Day 4. 


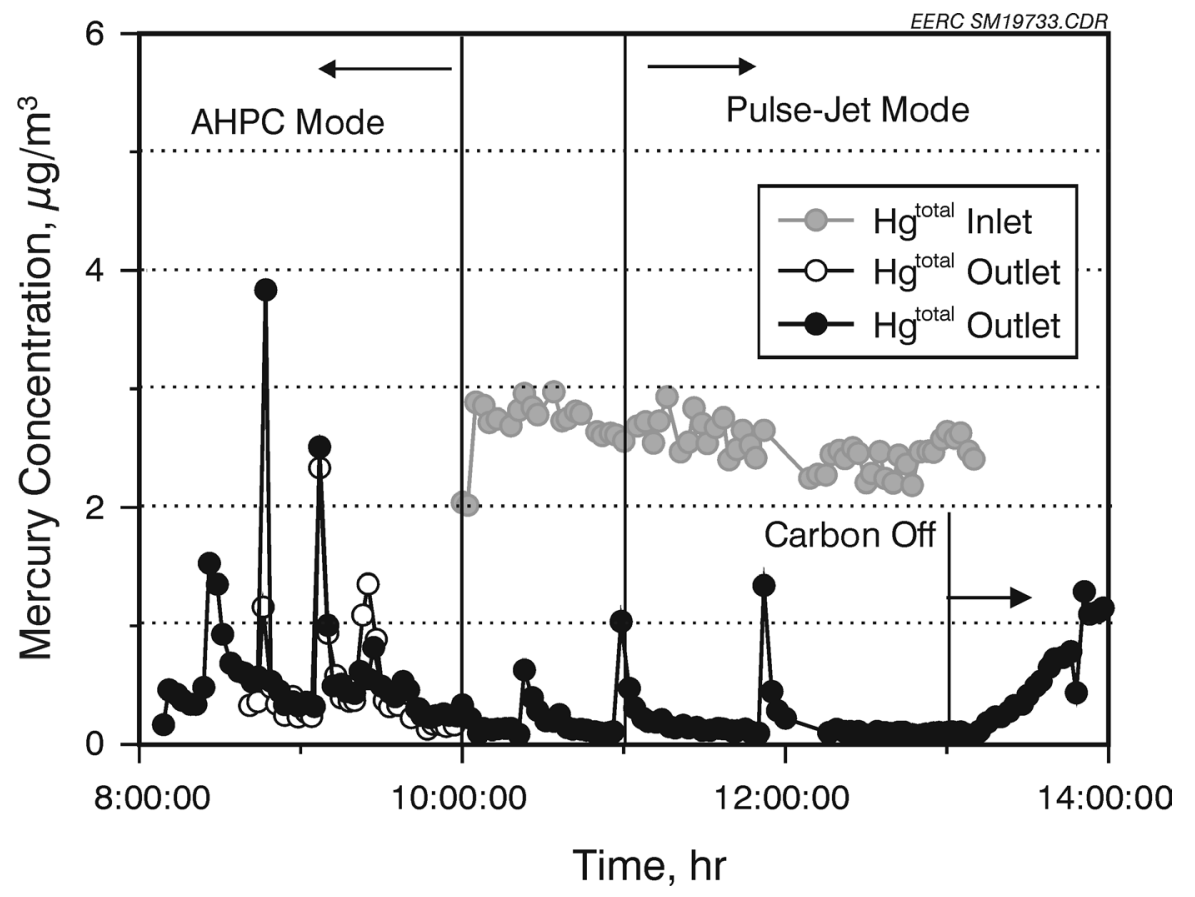

Figure 23. Hg species measurement by CEM - Day 5 .

\subsection{CONCLUSIONS AND DISCUSSION}

- The average inlet total mercury concentration of $12.3 \mu \mathrm{g} / \mathrm{Nm}^{3}$ (dry @3\% $\mathrm{O}_{2}$ ) was slightly below the theoretical value of $15 \mu \mathrm{g} / \mathrm{Nm}^{3}$. One possible reason for the difference is that the inlet sample location was at a point where the inlet dust loading may be somewhat biased low. Since about half of the mercury was particulate bound, a low dust loading measurement would also result in a low total mercury measurement. For example, if the dust loading was $30 \%$ low, this would translate to a $15 \%$ low bias in the total inlet mercury.

- The average inlet mercury speciation for seven samples was $55.4 \%$ particulate bound, $38.1 \%$ oxidized, and $6.4 \%$ elemental. The high level of particulate-bound mercury and oxidized mercury was somewhat surprising because for western PRB coals lower levels of particulatebound mercury and oxidized mercury are more typical. However, significant capture of mercury by the fly ash has been observed in previous EERC pilot tests as well as a number of coal-fired plants burning western fuels. Possible factors that determine the level of particulatebound and oxidized mercury include coal type, boiler type, $\mathrm{HCl}$ (as well as other flue gases), temperature, and amount of carbon in the fly ash. The current level of understanding of how these factors work together is insufficient to explain the observed mercury speciation for individual plants.

- A carbon injection rate of $1.5 \mathrm{lb} /$ million acf corresponds to a carbon-to-mercury ratio of approximately 2500 for the measured inlet mercury. With this carbon injection rate, from $91 \%$ to $97 \%$ total mercury collection efficiency was achieved compared to $49 \%$ removal for the 
baseline case. Even though the carbon addition rate was low, the carbon was highly effective at removing mercury. The data show that the carbon was effective at removing both elemental and oxidized mercury.

- Mercury removal with carbon removal in AHPC mode was 91\% and 92\% on Days 2 and 4 compared to $97 \%$ on Day 4 in pulse-jet mode. At first glance, this would seem to indicate that the pulse-jet configuration is better than the AHPC for mercury removal. However, in the pulse-jet mode, the residence time in the duct and chamber was twice as long and the temperature was also about 11EC (20EF) lower because of the lower flow rate. Both the longer residence time and lower temperature would be expected to lead to better mercury capture. On Day 5, the unit was operated in both modes at the same flow rate, which resulted in 94\% capture in AHPC mode and 95\% capture in pulse-jet mode. From these results, it can be concluded that both modes provided excellent mercury capture, at least for short-term tests, and there was no difference in mercury capture between the two modes. The conditions that produce the best collection efficiency with activated carbon are not well known. Previous pilot and field data indicate that the level of mercury capture with carbon is highly dependent on the coal type, other flue gases present, temperature, contact geometry, and residence time, but no model is available that can employ these factors to predict the level of capture for a specific configuration.

- These short-term tests are highly encouraging because they prove that excellent mercury removal can be achieved with very low addition rates of carbon injected upstream of the AHPC. Further testing is needed to demonstrate that the high level of mercury removal can be maintained over the longer term and that the carbon injection will not have any adverse effect on the longer-term operation of the AHPC. Since the conditions that lead to good mercury capture with carbon are not well known, at this point the results should not be generalized to other coals or plants. 